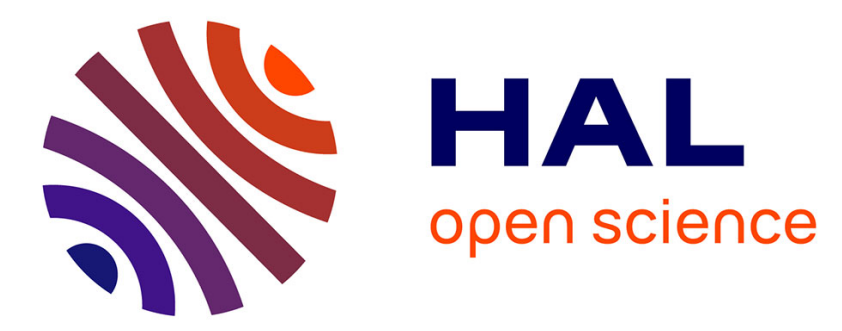

\title{
BPRIM: An integrated framework for business process management and risk management
}

\author{
Elyes Lamine, Rafika Thabet, Amadou Sienou, Dominik Bork, Franck \\ Fontanili, Hervé Pingaud
}

\section{- To cite this version:}

Elyes Lamine, Rafika Thabet, Amadou Sienou, Dominik Bork, Franck Fontanili, et al.. BPRIM: An integrated framework for business process management and risk management. Computers in Industry, 2020, 117, pp.1-17/103199. 10.1016/j.compind.2020.103199 . hal-02477509

\section{HAL Id: hal-02477509 \\ https://imt-mines-albi.hal.science/hal-02477509}

Submitted on 16 Mar 2020

HAL is a multi-disciplinary open access archive for the deposit and dissemination of scientific research documents, whether they are published or not. The documents may come from teaching and research institutions in France or abroad, or from public or private research centers.
L'archive ouverte pluridisciplinaire HAL, est destinée au dépôt et à la diffusion de documents scientifiques de niveau recherche, publiés ou non, émanant des établissements d'enseignement et de recherche français ou étrangers, des laboratoires publics ou privés. 


\title{
BPRIM: An integrated framework for business process management and risk management
}

\author{
Elyes Lamine ${ }^{\mathrm{a}, \mathrm{b}, *}$, Rafika Thabet ${ }^{\mathrm{f}, \mathrm{d}}$, Amadou Sienou $^{\mathrm{c}}$, Dominik Bork ${ }^{\mathrm{e}}$, Franck Fontanili ${ }^{\mathrm{b}}$, \\ Herve Pingaud ${ }^{\mathrm{a}, \mathrm{f}}$ \\ a Toulouse University, Institut National Universitaire Champollion, ISIS, Rue Firmin-Oulés, 81104 Castres, France \\ b Toulouse University, IMT Mines Albi, Department of Industrial Engineering, Route de Teillet, 81013 Albi Cedex 9, France

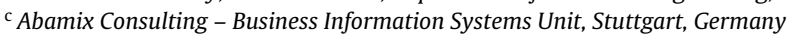 \\ d University of Sousse, ISITCOm, MARS Research Lab, Route G.P.1, 4011 Hammam Sousse, Tunisia \\ e University of Vienna, Faculty of Computer Science, Research Group Knowledge Engineering, Währingerstrasse 29, 1090 Vienna, Austria \\ ${ }^{\mathrm{f}}$ Toulouse University, INPT, CNRS, LGC, F-31432 Toulouse Cedex 04, France
}

Keywords:

Business process management Enterprise risk management

Risk-aware business process management

Model-driven engineering

Meta-modeling

Medication-use process

\section{A B S T R A C T}

Enterprise engineering deals with the design of processes which aim to improve the structure and efficiency of business organizations. It develops approaches based on modeling techniques, particularly on business process modeling, to ensure the quality and the global consistency of enterprise strategies and expectations. Nowadays, risk consideration in enterprise engineering is a growing concern since the business environment is becoming more and more competitive, complex, and unpredictable. To face this concern, a paradigm named risk-aware business process management (R-BPM) has recently emerged. It seeks to integrate the two traditionally isolated fields of risk management and business process management. Despite the significant benefits that can arise from the use of R-BPM, it suffers from a lack of solid scientific foundations and dedicated tooling. This present research work contributes to bridging that gap in a twofold way: (i) by establishing the BPRIM Business Process-Risk Integrated Method framework, and (ii) by designing a dedicated tool, named ADOBPRIM which supports the efficient application of the BPRIM framework. This paper first comprehensively presents the foundation of BPRIM which is based on three main components and, secondly, its dedicated tool ADOBPRIM which was designed using the ADOxx meta-modeling platform. An evaluation with a real case study in the health care domain shows the relevance of the methodological framework.

\section{Introduction}

Business process management (BPM) is both a management discipline and a set of technologies that support managing by process [1]. It is a paradigm of enterprise engineering that consists of designing, implementing, controlling and improving business processes in order to increase the ability of the organization to achieve a global high level of performance. BPM has shown, over the past decade, to be a valuable approach to confer maturity and agility to organizations applying it [2].

In the context of BPM, a business process is a symbolic resource, designed to coordinate value production by organizations $[3,4]$.

\footnotetext{
* Corresponding author at: Toulouse University, Institut National Universitaire Champollion, ISIS, Rue Firmin-Oulés, 81104 Castres, France.

E-mail address: elyes.lamine@mines-albi.fr (E. Lamine).
}

However, the value creation is threatened whenever the process is exposed to unexpected events, whose occurrence can lead to an interruption of business activities. Hence, a business process is somehow subject to the same qualification and availability requirements as a hardware, software or human resource before commissioning. Although this observation is widely shared, using the process model in order to preserve the level of business performance is at present an original approach of business process management. However, there exists a quite recent awareness, promoted by the principle of business continuity management (BCM) $[5,6]$, which significantly drives the use of concepts from the enterprise risk management (ERM) within business process management concepts. ERM is indeed a systematic approach that sets the best course of actions under uncertainty by identifying, assessing, understanding, acting on, and communicating risk issues [7]. It may confer robustness required to maintain performance in a changing environment, not necessarily predictable, dominated 
by the hazard of internal and/or external sources. These observations led to the emergence of the risk manager job profile in large organizations. Having its roots in areas such as project management, finance, and industrial safety, risk management has evolved toward an established activity in its own right, cross-cutting and transcending professions within organizations. Indeed, risk management is of increasing importance as business processes tend to be outsourced into the cloud [8] or executed via Internet of Things devices [9].

In light of many events which happened in the last decade, leading to large scandals, it is becoming essential to bring the risk management practices closer to the business process management domain [10]. Several studies [11-13] outline that the identification of risks contributes to a better understanding of potential threats to business objectives. Identification is reached by eliciting useful knowledge for both the risk and business process managers. In this context, clarifying the many relationships between risks and business processes in their nominal operating condition is a major issue and a prerequisite to controlling risks. Regarding risk analysis, the resulting integrated risk and business process model will help control various risk factors and danger quantification in view of the exposure to given risks. In fact, the risk manager will use the risk factors knowledge in the context of processes to better conduct risk analysis and handling. Regarding the treatment of risks, the model will also provide useful knowledge for preventive and curative actions, since the risk context (i.e., the business process and its environment) is known and formalized in the model. From a business process management point of view, process engineers and process managers could refer to risk models for decisions concerning process engineering and control due to a better understanding of the relationships between processes and risks.

The need to embed risks into business process models, has motivated the development of risk-aware business process management (R-BPM) [14,15], which aims at supporting risk and business managers at different life cycle phases and organizational levels. R-BPM promotes risk consideration in the early stages of business processes management and enables robust and efficient business process management within uncertain and highly changing environments. Although the objectives of R-BPM are very ambitious, scientific research in this field, compared to what is published in BPM and ERM, is scarce and in premature stage. Indeed, studies in this area are confined to a field of specific applications (finance, IT, etc.) or specific stages of the life cycle (design-time, assessment, etc.). There is no methodological framework to structure and equip this new paradigm in a comprehensive manner and there is no integrated approach covering both the different stages of the BPM life cycle and the ERM life cycle.

Since our research contributes to the promotion of this new field, this paper introduces the field of risk-aware business process management and its practical considerations. This is a proposition to set the first foundations of a new framework called BPRIM (Business Process-Risk Integrated Method). BPRIM contributes bridging the gap of mature and comprehensive R-BPM approaches by strengthening the business process management approach and including risk management capabilities. Integrating models from two disciplines is not new in itself. It is well known and used in, e.g., model-driven enterprise engineering and enterprise architecture management, where models facilitate the integrated description and control of an organization's structure, processes, applications, systems and techniques [16]. BPRIM supports also both human-interpretable graphical models that act as machine-interpretable knowledge base. Our proposal therefore fits into the call for next-generation of enterprise information systems "which embed modelling tools and algorithms for model analysis" [17,p. 77].
This paper presents recent achievements of an ongoing longterm research stream - first ideas were presented in [18-20] - devoted to model-driven enterprise engineering through integrated consideration of risk and process management. The integration aims to lead to an improved performance, thanks to the use of a common shared knowledge. Drawing upon the principles of enterprise architecture, the BPRIM framework provides insights and value-driven models able to support risk and process managers in their duties. BPRIM is based on an integrated management method and a dedicated modeling language. Beyond an up-to-date literature overview on R-BPM, further main contributions of this paper are the provision of a comprehensive overview of the revised foundations of the BPRIM framework, an introduction of a modeling tool supporting BPRIM called ADOBPRIM, and an industrial real-world case study showing the application of BPRIM in the health care sector. The BPRIM framework is built on three major pillars: (1) a coupling of risk and business process management life cycles; (2) a unified meta-model for risk and business processes; and (3) a modeling language for the description of risky situations from the common perspective of risk and process experts.

The remainder of this article is structured as follows. First, we give in Section 2 an overview of the related works on the coupling of BPM and ERM and argue about the importance of a methodological support to the integrated management of process-risks. In Section 3, we focus our endeavour on the detailed presentation of the main components of the BPRIM framework. Section 4 then introduces the ADOBPRIM modeling tool realized with the metamodeling platform ADOxx. An evaluation of the use of the BPRIM framework through a real case study from the health sector and a discussion of its current strengths and limitations are presented in Section 5. Eventually, Section 6 concludes the paper and outlines directions for future work.

\section{Background and related works}

In this section, we introduce the necessary theoretical foundations of conceptual modeling before giving a brief synopsis of the relevant literature considering risk-aware business process management (R-BPM).

\subsection{Conceptual modeling methods}

Conceptual modeling refers to the creation of an abstract visual representation of selected real-world phenomena. Conceptual models are created by humans and serve the purposes of specification and understanding of complex systems by applying abstraction [22]. In this regard, conceptual models respect the cognitive capabilities of human beings. The creation of a conceptual model is guided by a conceptual modeling language, comprising the syntactic concepts (or abstract syntax), notation guidelines (or concrete syntax) and semantic specifications. In a broader sense, adding a modeling procedure as well as mechanisms \& algorithms that process the knowledge codified in the conceptual models derives what is being referred to in the following as a conceptual modeling method. Fig. 1 visualizes the components of a modeling method and their relationships.

Conceptual modeling has emerged from being applied in general-purpose settings, e.g., in the database domain to define an abstract representation for the relational algebra or in the software engineering domain to define the structure of software systems prior to their implementation. It enables diagrammatic representations of formalized domain-specific knowledge that is intersubjectively understandable and machine processable [23]. In recent years, a number of domain-specific conceptual model- 


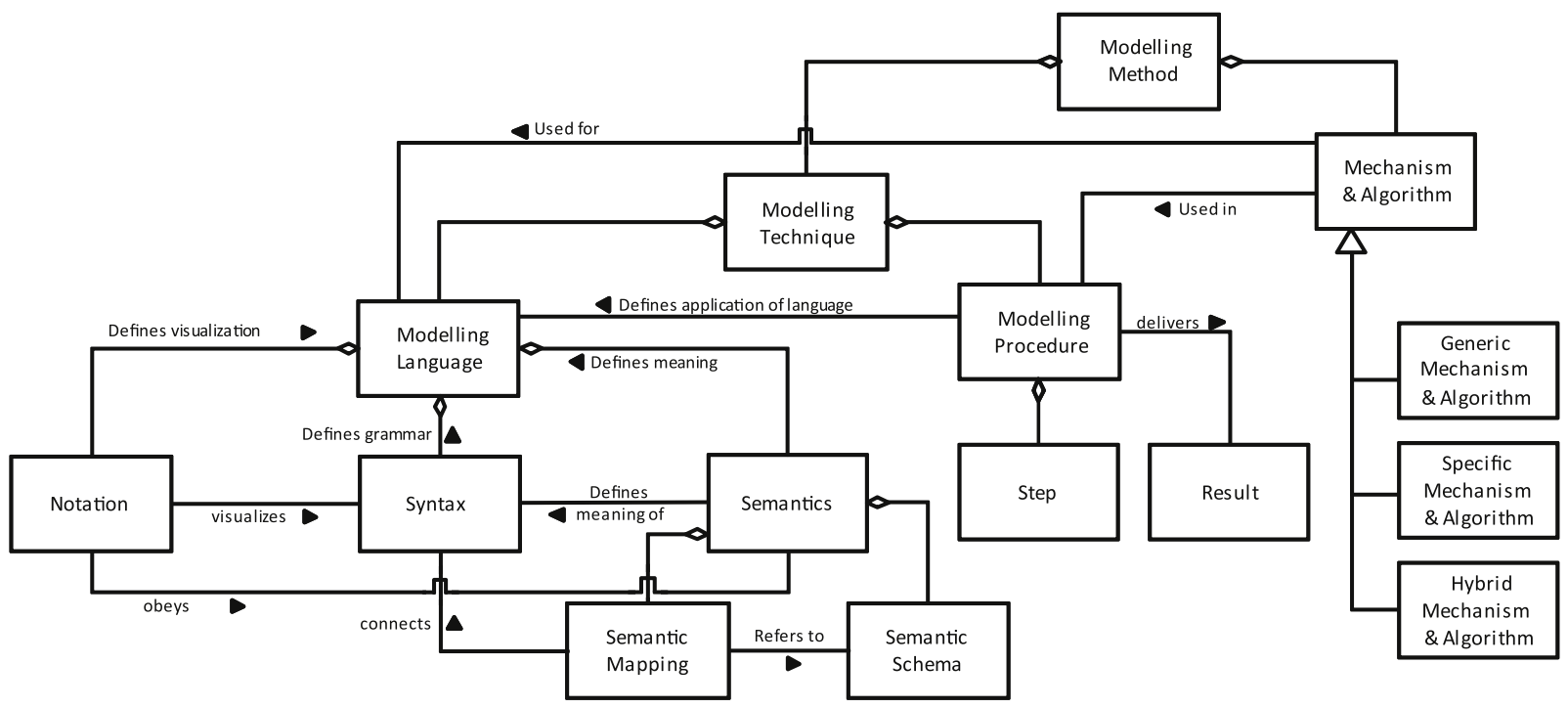

Fig. 1. Components of modeling methods [21].

ing languages (DSML) and methods have been researched (cf. [24] for a selection of DSMLs of the OMiLAB [25]). The strength of such DSMLs is the possibility to align all components of the modeling method, i.e., modeling language, modeling procedure, and mechanisms \& algorithms (see Fig. 1), to the specific needs, requirements, and aptitudes of the specific domain and identified stakeholders. This understanding of a modeling method has laid the foundation for developing the BPRIM framework which will be introduced in Section 3.

\subsection{R-BPM motivation}

Business process management promotes reactivity and operational flexibility of organizations. It aims at improved overall performance and fulfilled external stakeholders' expectations. Managing business processes, concerns understanding the relationship between the location of value creation and the value itself [2]. This is achieved roughly through the steps of planning, designing, and execution. By contrast, enterprise risk management (ERM) seeks to improve decisions in an uncertain environment for handling the preservation of value. ERM establishes a balance between the expectations in a range of acceptable variations in value and ensures effective deployment of resources. Risk management promotes a good appreciation of the richness and the fineness of the relationship between value and value preservation [26].

These two management approaches intrinsically seem to be independent from each other and form two complementary fields. However, an integrated approach would enable managers to improve decisions in the value creation activities in order to increase the ability of preserving the value itself. Business process management designs, deploys, and manages the value creation process, while risk management looks for the preservation of value. A couple of recent research works have delivered interesting discussions on the challenges of integrating BPM and ERM - giving birth to the risk-aware business process management (R-BPM) research field.

R-BPM is widely defined as the integration of risk aspects into business process management in order to increase the riskawareness of an organization's business processes. This integration enables the efficient identification, detection, and management of process-related risks [27]. R-BPM promotes risk consideration in all stages of business processes management and enables a robust
Table 1

R-BPM approaches categorized according to the BPM life cycle stage where they consider risk, in chronological order.

\begin{tabular}{ll}
\hline BPM life cycle stages & \\
\hline Design-time & Run-time \\
\hline Rosemann and Muehlen [11] & Jans et al. [28] \\
Jakoubi et al. [13] & Wickboldt et al. [29] \\
Panayiotou et al. [30] & Rogge-Solti and Weske [31] \\
Weiss and Winkelmann [32] & Haggag et al. [33] \\
Rotaru et al. [34] & Pika et al. [35] \\
Strecker et al. [36] & Conforti et al. [37] \\
Fenz [38] & Kim et al. [39] \\
Bai et al. [40] & Metzger and Bohn [41] \\
Shabnam et al. [42] & \\
Lhannaoui et al. [43] & \\
Shah et al. [44] & \\
Pittl et al. [45] & \\
\hline
\end{tabular}

and efficient business process management within an uncertain environment.

\subsection{Current R-BPM approaches}

R-BPM approaches aim to extend conventional BPM approaches by establishing awareness for external, contextual elements that impact the way processes are executed or managed. Generally, RBPM approaches are categorized according to the BPM life cycle [15] stage where they integrate risk aspects. Two categories are distinguished in the following (see Table 1):

- R-BPM approaches at the design-time stage: approaches which focus on risk management during the design-time phase of business processes, often referred to as risk prediction.

- R-BPM approaches at the run-time stage: approaches which focus on risk management during and after the execution of business processes, often referred to as risk monitoring.

As shown in Table 1, most recent R-BPM approaches concentrate on the design-time stage of the BPM life cycle. Obviously, managing risks in business process starts by a convenient representation of risks and their characteristics in business process models. This representation allows for an understanding of the risk origins in business processes, their impact on these processes, and the con- 
trol and mitigation strategies in place. The approaches shown in Table 1 developed different strategies to deal with this issue.

An extensive literature review in the area of risk-aware BPM is presented in $[14,15]$. We can note from their findings that there are only a limited number of articles dealing with this area of research. These R-BPM approaches could be classified into two categories with regard to the risk modeling consideration: (1) those that introduce new risk-related constructs in order to incorporate risk information into the business process model; and (2) those that attempt to reason risks using risk analysis methods or techniques without the introduction of new constructs. Because the research and practice of risk-aware business process modeling is still very limited, the level of research in this area requires further exploration, as outlined in their conclusions.

Ref. [11] is the first work that deals with risk-aware business process modeling. In this work, Event-driven Process Chains (EPC) are extended to consider risks, enabling the assignment of risks to individual parts of the EPC process. In the same context, several other works have also proposed new graphical notations to represent risks by the EPC language such as [34]. In [34], the ValueFocused Process Engineering (VFPE) model, which is based on the extended EPC model, is further extended in order to formalize the risk concept within business process models. The proposed approach attempts to represent risks in goal-oriented process models. It also proposes several constraints to formalize the notion of a risk-aware EPC model. This approach provides a procedural method for identifying process-related risks and associating those risks with the business process model. The proposed model is related to the model in [11].

In contrast, in [46-48], a semi-formal extension of risk-related modeling constructs to the Business Process Model and Notation (BPMN) standard is developed. By applying these constructs, one can encode risk-related information into a process model, such as the various risk events that can occur and the mitigation actions that can be taken. Varela-Vaca et al. [49,50] also propose an extension of BPMN with information system security risk domain model (ISSRM) concepts [51]. The authors illustrate how the extended BPMN could express assets, risks and risk treatment on few running examples related to an Internet store's assets confidentiality, integrity, and availability. Their proposal would allow system analysts to understand how to develop security requirements to secure important assets defined through business processes.

Similarly, Marcinkowski and Kuciapski [52] and Altuhhov et al. [53] propose a BPMN extension for risk handling. In these works, the authors take advantage of the functionality of the error event as it is of particular importance in risk management. Accordingly, identified risks are assigned to processes, sub-processes, or activities to which these risks apply. The standard BPMN language was furthermore extended with the modeling construct of risk factor, characterizing a potential risk in terms of type, likelihood, and impact on business process as a whole. Risk factors are assigned to BPMN sequence flows.

In [32], the Semantic Business Process Modeling Language (SBPML) is extended with a number of risk-related constructs and graphical notations such as risk events, risk control actions, and risk types. This approach addresses the operational risks in the specific context of the finance domain.

In [54-56], the Risk-Oriented Process Evaluation (ROPE) approach is introduced, which proposes a three-layer model to capture the notion of risk within a business process model. The top one is the business layer which consists of business process activities. These activities are decomposed into their corresponding Condition, Action, Resource and Environment (CARE) elements to form the middle layer of the model. The bottom one is called the Threat Impact Process layer that captures various threats that may affect the corresponding CARE elements and the counter measure activ- ities. The authors described a simulation process for assessing the impact of threats on the process activities.

A comparative study of the most relevant approaches related to BPRIM is provided by Table 2. This comparison is carried out in accordance with the following criteria whose first three items match with the main components of modeling methods as proposed in [21]:

- Modeling Language: indicates which modeling language is used to represent risk and business process.

- Modeling Procedure: indicates whether the approach describes the steps for creating models using the modeling language (i.e., a life cycle).

- Mechanisms and Algorithms: indicates whether the approach provides functionality to use and evaluate models.

- Application Domain: indicates the application domain.

- Risk constructs characterization: indicates the degree of risk characterization in business process models.

- Risk Formalization: indicates whether the approach proposes novel constructs to capture risk-related information. We assume that the proposed risk constructs are formalized in terms of abstract syntax - whether the approach specifies the risk construct using appropriate formal description techniques [60]; concrete syntax (or Notation) - whether the approach specifies the graphical representation of the proposed risk constructs [60]; and semantics - whether the approach specifies the meaning of and operations applied upon the proposed risk constructs using appropriate formal techniques.

- Tool Support: indicates whether the approach is supported by a tool that permits the creation of models.

The symbol (-) indicates that an approach does not support a criteria, the symbol (+) indicates that an approach largely supports a criteria, and the symbol $( \pm)$ indicates that an approach partially supports a criteria.

\subsection{Summary of R-BPM approaches}

Overall, the presented approaches mainly concentrate on the concrete syntax definition of risk constructs. For instance, the approach proposed in [57], proposes a set of graphical notations to represent risk elements that can be associated to business process activities. However, few approaches tried to formalize the abstract syntax of risk constructs. Among these few, we highlight the works of Cope et al. [47,48], Strecker et al. [36], Betz et al. [58], and Weiss and Winkelmann [32] which design a meta-model to formally [23] specify the abstract syntax of their risk constructs. We furthermore found that, with the exception of the work of Pittl et al. [45] and Weiss and Winkelmann [32], the majority of the recent R-BPM approaches are not guided by any existing risk standards. Lastly, only very few of these approaches (4 out of 11) have full tool support provided. As a consequence, we are highlighting a serious R-BPM research gaps.

To advance the theory of risk in the business process design context and establish sound foundations for R-BPM, three research questions have to be answered. For every research question, we depict the contribution that this paper makes in this respect:

1. How can the two life cycles of BPM and ERM be coupled? This article proposes a dedicated R-BPM life cycle.

2. What are the relationships between the BPM and the ERM concepts? This article proposes a unified meta-model for integrated risk and business process management. 
Table 2

Comparative overview of risk integration in recent R-BPM approaches.

\begin{tabular}{|c|c|c|c|c|c|c|c|c|c|}
\hline \multirow[t]{2}{*}{$\begin{array}{l}\text { R-BPM } \\
\text { approaches }\end{array}$} & \multirow[t]{2}{*}{$\begin{array}{l}\text { Application } \\
\text { domain }\end{array}$} & \multicolumn{3}{|c|}{$\begin{array}{l}\text { Risk-aware business } \\
\text { modeling method }\end{array}$} & \multirow{2}{*}{$\begin{array}{l}\text { Risk constructs } \\
\text { characteriza- } \\
\text { tion }\end{array}$} & \multicolumn{3}{|c|}{ Risk formalization } & \multirow[b]{2}{*}{ Tool support } \\
\hline & & $\begin{array}{l}\text { Modeling } \\
\text { language }\end{array}$ & $\begin{array}{l}\text { Mechanisms } \\
\text { \&algorithms }\end{array}$ & $\begin{array}{l}\text { modeling } \\
\text { procedure }\end{array}$ & & $\begin{array}{l}\text { Abstract } \\
\text { syntax }\end{array}$ & Notation & Semantic & \\
\hline $\begin{array}{l}\text { Jakoubi et al. } \\
{[57,56]}\end{array}$ & Generic & ROPE & - & - & \pm & - & + & - & \pm \\
\hline $\begin{array}{l}\text { Cope et al. } \\
{[47,48]}\end{array}$ & Generic & $\begin{array}{l}\text { Extended- } \\
\text { BPMN }\end{array}$ & \pm & \pm & \pm & + & + & - & - \\
\hline $\begin{array}{l}\text { Varela-Vaca } \\
\text { et al. }[49,50]\end{array}$ & $\begin{array}{l}\text { Security } \\
\text { Engineering }\end{array}$ & $\begin{array}{l}\text { Extended- } \\
\text { BPMN }\end{array}$ & + & \pm & \pm & + & + & \pm & + \\
\hline $\begin{array}{l}\text { Weiss and } \\
\text { Winkelmann } \\
{[32]}\end{array}$ & Finance & $\begin{array}{l}\text { Extended- } \\
\text { SBPML }\end{array}$ & - & - & + & + & + & - & - \\
\hline $\begin{array}{l}\text { Rotaru et al. } \\
{[34]}\end{array}$ & Generic & Extended-EPC & - & - & + & + & + & \pm & - \\
\hline Betz et al. [58] & Generic & Xnets & - & - & \pm & + & + & - & + \\
\hline $\begin{array}{l}\text { Strecker et al. } \\
{[36,59]}\end{array}$ & Generic & RiskML & - & - & - & + & + & - & - \\
\hline $\begin{array}{l}\text { Altuhhov et al. } \\
\text { [53] }\end{array}$ & $\begin{array}{l}\text { Security } \\
\text { Engineering }\end{array}$ & $\begin{array}{l}\text { Extended- } \\
\text { BPMN }\end{array}$ & \pm & \pm & \pm & + & + & \pm & + \\
\hline $\begin{array}{l}\text { Lhannaoui } \\
\text { et al. [43] }\end{array}$ & Generic & Extended-EPC & \pm & \pm & \pm & - & + & - & - \\
\hline Pittl et al. [45] & Generic & SWRL & + & \pm & \pm & + & + & + & + \\
\hline Shah et al. [44] & Manufacturing & $\begin{array}{l}\text { Extended- } \\
\text { IDEF3 }\end{array}$ & + & \pm & \pm & + & - & - & - \\
\hline
\end{tabular}

3. Which modeling method could support such a unified metamodel? This article proposed the BPRIM method and ADOBPRIM as a corresponding modeling tool.

\section{A unified framework for risk and business processes management}

This paper develops a comprehensive, unifying and modelbased framework named BPRIM for Business Process-Risk Integrated Method. It is a methodological framework based on the coupling of two typically separate parts - process management and risk management. This section describes the major components of the BPRIM framework: (1) the BPRIM life cycle (Section 3.1); (2) the BPRIM meta-model (Section 3.2); and (3) the BPRIM modeling language (Section 3.3).

\subsection{BPRIM life cycle}

Applying BPM and ERM typically follows a procedural approach, known as the BPM life cycle and ERM life cycle, respectively. When aiming to integrate BPM and ERM, one naturally faces the challenge of integrating both life cycles. In the specific case of BPRIM, the challenge was to develop a life cycle that enables the design of risk-aware business process models. The BPRIM life cycle couples steps of the process management life cycle with those of risk management. This coupling can be made according to one of the following two approaches:

1. A unification approach that fuses different states of each individual life cycle to form a coherent whole. This approach requires the reconsideration of the logical activity sequences of each individual life cycle. The unified life cycle induces a significant change in the practices of BPM and ERM actors. It is a prescriptive approach, white box-like.

2. An integration approach is based on the principle of the black box and attempts to link the two individual life cycles by working on interfaces seeking to build relationships between their outputs and their respective inputs. This approach, which is descriptive, strengthens communication between the teams in charge of the cycles while minimizing changes to each individual life cycle.

In order to maintain the autonomy of business experts and risk experts and to facilitate the appropriation of BPRIM, we adopted the integration approach to design the BPRIM life cycle $[18,20]$. The underlying assumption was that any activity is prone to risk and there is no risk without an associated activity. We therefore naturally chose the business process management life cycle as starting point. Consequently, the risk management life cycle will be driven by the process management life cycle. Indeed, in order to produce a new representation of the organization, i.e., the "To-Be" model, the description of how the organization works effectively, i.e., the "As-Is" model of the organization, must be defined before risks can be considered. Besides, it is the same vision that has been taken in the majority of the work on R-BPM $[13,61,15]$. This brings us to distinguish two major phases in the final cycle: a conceptual phase associated with the design of the processes which are prone to risks; followed by an operational phase concerned with the steering process led by risks.

In this work, the emphasis is on the conceptual phase of Riskaware Business Process Management. In order to define the life cycle steps of this phase, we started from the BPM and the ERM life cycles that are most commonly accepted by their respective scientific communities, namely those proposed in $[2,62]$. Then, we adopted a Structured Analysis for Real Time (S.A.R.T.) method to study the information flows that can occur among the stages of the two cycles. This choice was motivated by the fact that we wanted to focus on the identification of existing interfaces between the different stages of the two isolated cycles and, in particular also, where data comes from, goes to, and where it will be stored. The S.A.R.T. method is a structured analysis and design method which is widely used to graphically model these kind of data transformations in a system. It includes data-flow diagrams (DFD) to depict the data flow and supports decomposition mechanisms to display the inputs-outputs details of each component of the studied system [63].

Accordingly, we assumed that interaction will be primarily embedded in a set of models shared by the two cycles according 


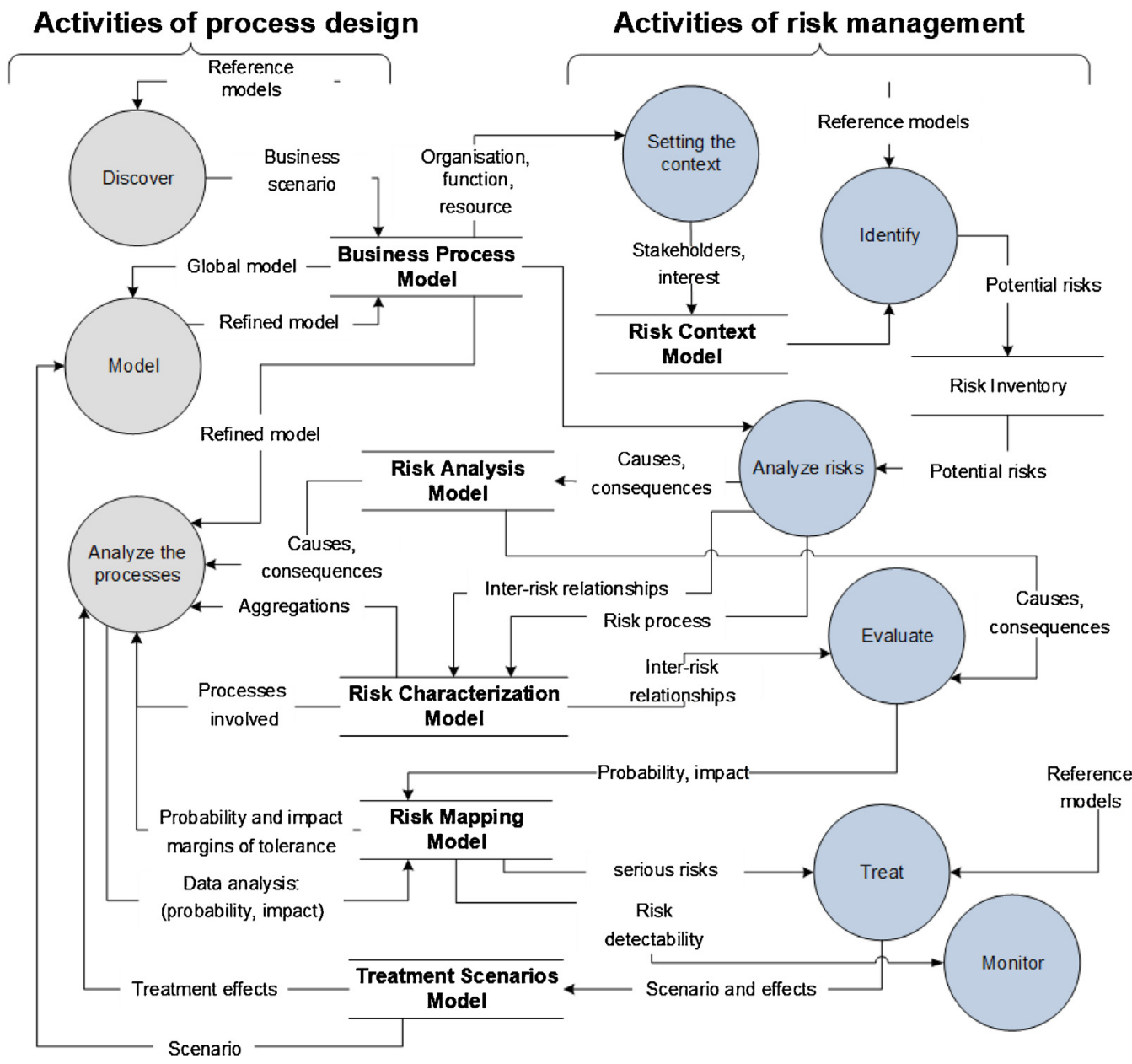

Fig. 2. Overview of interactions between process design stages and risk management stages.

to a supplier-consumer relationship. The result visualized in Fig. 2 is an alternating digraph which specifies all interactions between the two life cycles. The arcs are labelled to indicate the usage and storage of data in the target life cycle step or BPRIM model. Common models (items in bold in Fig. 2) to steps of process design and risk management are placed in the centre of the graph. Generally, the BPRIM models act as database for the data to be created, used, and shared. The detailed description of these BPRIM models is given in Table 4. An analysis of the graph in Fig. 2 leads to the following observations:

- The business process models are the main inputs for the "Setting the context" step of the ERM life cycle which aims to establish the scope of the risk management project. The steps of discovering business scenario, modeling processes, and setting the risk context are similar since they result in a set of models which support process and risk analysis.

- The steps of process analysis and risk analysis are related, which can be observed by the strong connectivity within these two stages in Fig. 2. Indeed, the analysis step is based on the knowledge of risk analysis and risk assessment to guide the design of a new target process. In addition, the risk analysis is based on the results of the process analysis to determine risk levels, or propose criteria for classification of risks in a risk map.

On the basis of these observations, we have completed this first flow-oriented modeling step in order to propose a coupling between the two life cycles which takes into consideration the temporal chronology. Indeed, the DFD-based modeling does not allow to study the temporal logic of the processes themselves. We chose Business Process Model and Notation (BPMN) to establish these models which are displayed in Fig. 3. Following the temporal chronology of the comprehensive process and according to the similarity of the purposes sought by "Discover" and "Setting the context" activities, these latter shall be meld with "Model" activity into a scoping step that aims at setting up a context common to process design and risk management. The business model and the context model of risk are the main output of this common step. By the same logic, "Analyse the processes" and "Analyse risks" activities shall be merged into a single activity. This latter should be incorporated then into a more comprehensive step which aims to assess process-related risks.

The comprehensive analysis of the BPM and ERM life cycles models guided the design of the generalized Business Process Risk Integration Method (BPRIM) life cycle for risk-aware business process management at design-time (see Fig. 3). The iteractive BPRIM life cycle is triggered by a process-engineering environment and gradually enriched by a risk management process. It consists of the following four phases:

1. Contextualize: This phase aims at setting up the context of the joint management of risks and processes. It can be triggered by a decision affecting a significant change of the context such as the establishment of a new treatment alternative.

2. Assess: This phase comprises the identification and implementation of the joint study of risks and processes to understand 


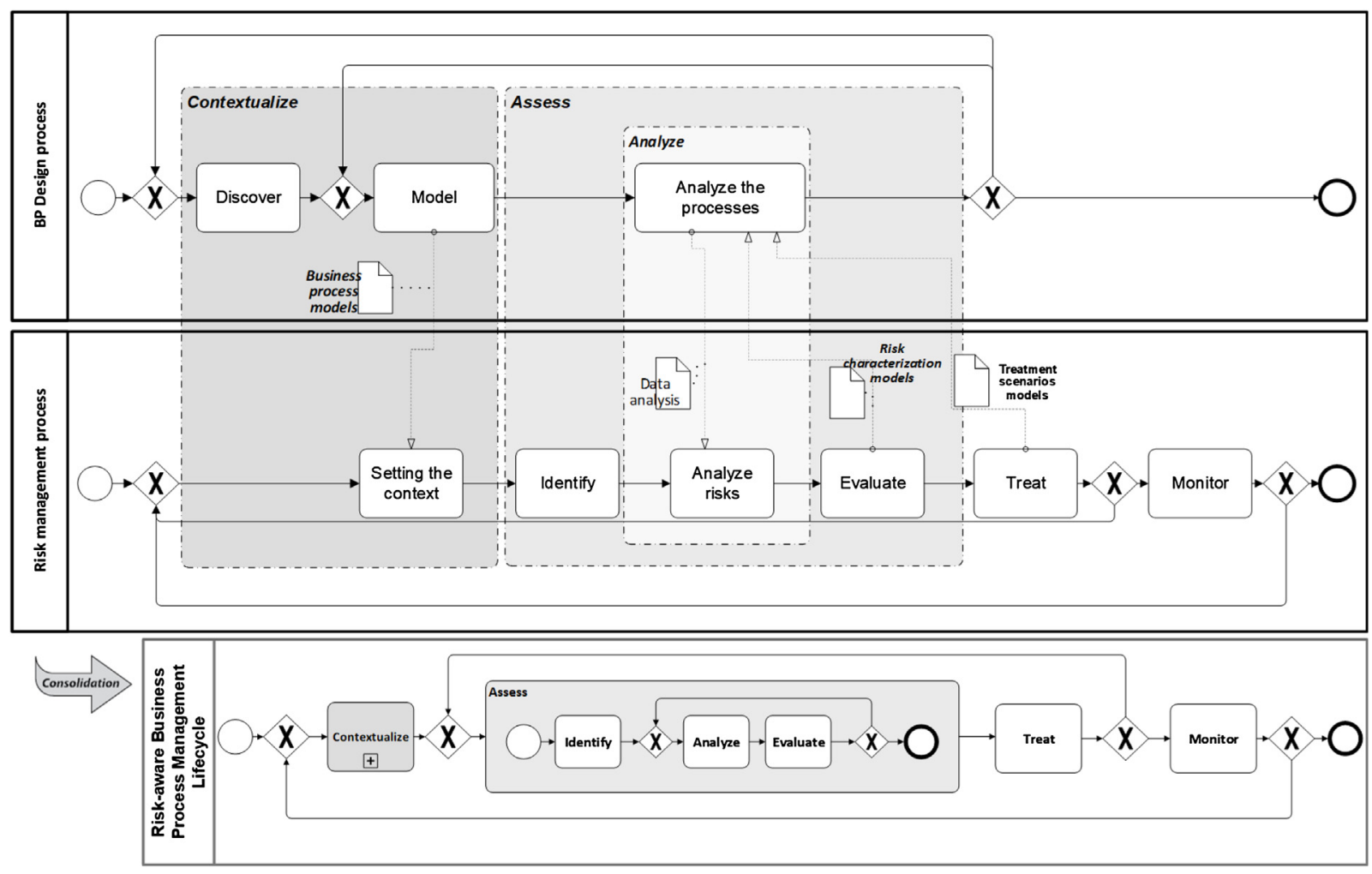

Fig. 3. BPRIM life cycle.

their interactions and possible impact. The outcome is necessary to prioritize risks and foster the development of risk treatment alternatives.

3. Treat: This phase considers the definition of a set of treatment alternatives which triggers a new iteration of the assessment phase in order to understand the possible impact of the alternatives. This phase can lead to a reframing - meaning going back to the contextualization phase - which would require the implementation of risk handling actions. This is being done by fitting the models or by defining treatment alternatives. The risk handling scenarios that require no change of models will be stored to be triggered once needed.

4. Monitor: In this phase, a monitoring takes place, checking whether decisions regarding treatment alternatives have been taken according to predefined instructions. It also ensures those alternatives which cannot be implemented through a simple change of process models at design-time will be transferred to be considered at deployment time. It is therefore a control phase, which provides guidance for refinement of the models or the transition to the implementation phase. However, at run-time phase, the handling of risks that evolves over time is carried out by a change in the model, which is compliant with the ISO 31000 specification. In other words, knowledge related to the model evolves with the real system behaviour (as depicted in Fig. 3 by the cycle loop after the monitor activity). This is also the case for risks that have not been anticipated yet.

As we noted earlier, the information exchanged between these phases will be essentially contained in a wide range of BPRIM models and as displayed in Table 4. Based on model-driven engineering principles, these models must conform to a meta-model, which integrates concepts related to both, business processes and risks. The meta-model supporting the BPRIM method is developed in the next section.

\subsection{BPRIM meta-model}

The BPRIM meta-model specifies the main concepts handled during the different stages of the BPRIM life cycle and the allowed relationships between them. It considers the static aspects of BPRIM which guide and constrain the development of models. The BPRIM meta-model puts forward a conceptual unification of risks and processes into a common meta-model allowing to comprehensively address the semantics of R-BPM artefacts. The BPRIM meta-model was based on one hand on the business process meta-model proposed in the ISO 19440:2007 standard [64] and on the other hand on our proposition of a risk meta-model $[18,65]$.

The ISO 19440:2007 standard [64] provides an abstraction level which fully matches conceptual modeling of business processes from the semantic point of view and offers guidelines which meet an organization's needs. It consists of four parts, each linked to a point of view of the enterprise. The Organizational Management View describes the responsibilities and the authorities in the domain of the enterprise. The Information View describes the elements of information that represent the objects of the enterprise (material and informational objects) that are produced and used for the operations of the enterprise. The Resource View describes the assets and the resources of the enterprise (e.g., human resources, technology components). The Functions View describes the business processes, their functionality, behaviours, inputs, and outputs.

Concerning risk modeling, we have noted a lack of conceptual models playing a similar role as ISO 19440 for business processes modeling. This observation led to the proposition of a meta-model for risk, which is based on the study of the internal structure of risks. Fig. 4a conceptualizes our vision of a risk meta-model. It defines risk with regard to the causal and the consequence perspectives. The causal aspect consists of risk factors that are favourable for the occurrence of a given risk event. Here, an event is an occurrence, which may cause state transitions within a system. This risk event is considered being the root cause of a risk situation, which 

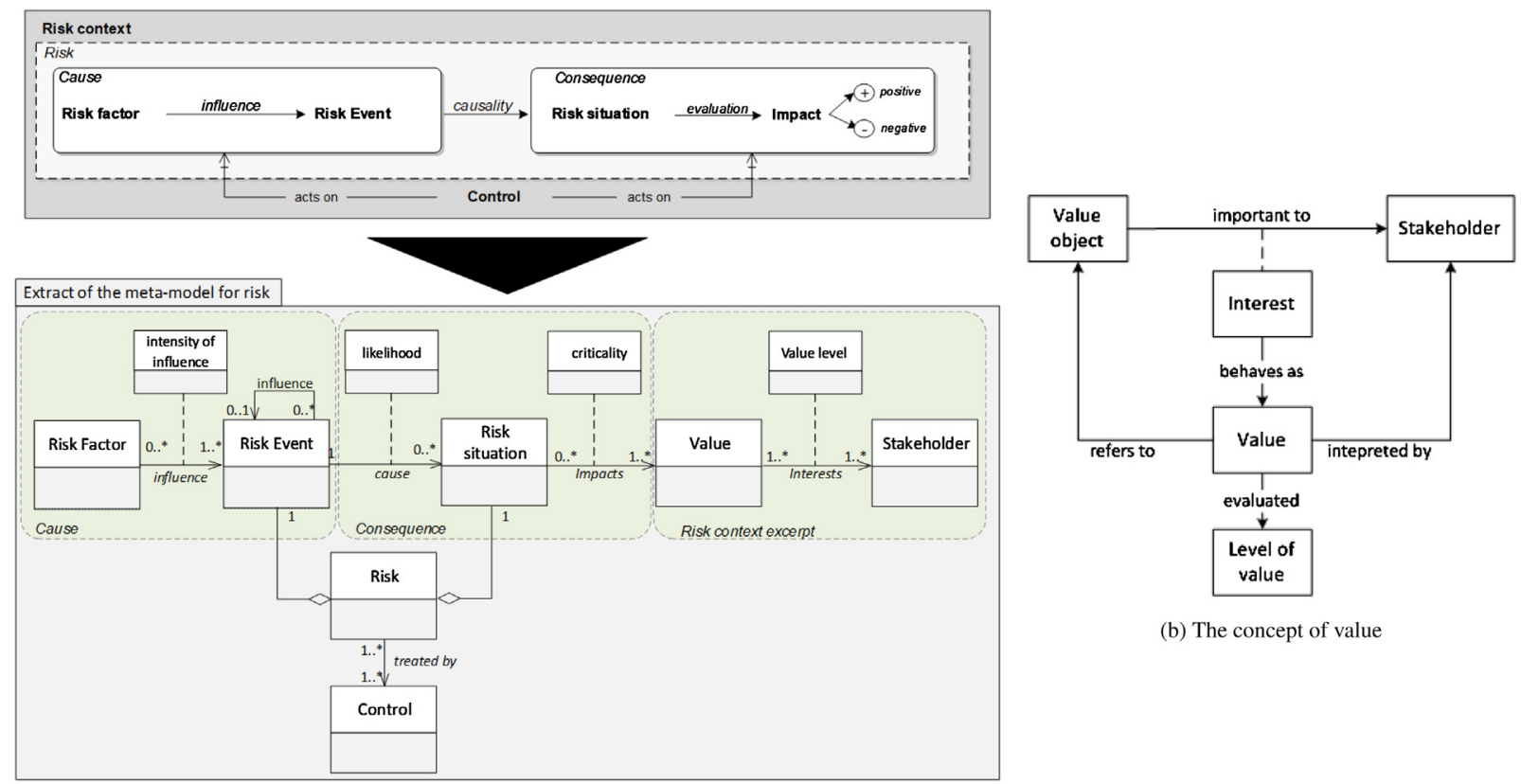

(b) The concept of value

(a) Excerpt of the Risk Meta-Model

Fig. 4. Risk meta-model excerpt (a) and specification of the concept of value (b).

describes a possible state of the system under study. The state is evaluated in terms of impact (positive or negative). The causality and the impact is interpreted by a set of actors while considering their interests, which is defined in the context of risk. Handling the risk to be acceptable is achieved by making decisions with regard to establishing control mechanisms affecting the cause or the consequence.

A subsequent mapping of relationships between these two meta-models is based on the concept of Value. Undeniably, this concept of Value is a hotly debated issue in enterprise management (rules and values), in deployment of organizational strategy, in performance management, in design, in functional analysis, and in value-based management $[66,67]$. For example, we remind that business processes have been popularized as vectors of value creation by Hammer and Champy [68,p. 38], who states that "a business process is a collection of activities that takes one or more kinds of inputs and creates outputs that is of value for the customer".

Considering most definitions, value creation seems to be a main characteristic of business processes. However, the concept of value seems to be ignored while conceptualizing business processes. In general, value designates the assessment of a value object by a given stakeholder. This assessment is either quantitatively or qualitatively evaluated in terms of value levels. A value describes the interest of a stakeholder for a given object and is interpreted by stakeholders. In this work, we follow the conceptualization of value as shown in Fig. $4 \mathrm{~b}$.

Since a business process is a vector for value creation, a given object can be assessed different values by different stakeholders. For example, the performance is important for the process owner, while compliance is relevant to the quality manager and work safety to the risk manager. Furthermore, the consequence part of risk is evaluated in terms of impact. Since, risks are able to cause value modifications, it is easy to link a business process to a risk by defining the impact of the risk as a perception in the variation of the value level. Considering business processes, a risk is able to modify the value interpreted by a set of stakeholders. A risk may cause, for example, performance, quality or compliance variations. Riskaware business process engineering is expected to provide means so that such variations could be controlled.
This understanding of the value concept allowed us to establish the relationships between the concepts provided by business process management and risk management. Fig. 5 visualizes the core of the BPRIM meta-model for risk-aware business process management. Here, for instance, the business process is considered as being by itself a key value object of an organization. The values related to this object are expressed by key stakeholders of the organization. For clarification purpose, the process performance is for example a value. Any objects able to cause a performance variation is a risk factor that will increase the likelihood of occurrence of an instability (risk situation). Other meta-model elements contribute to semantically relate concepts of risk and process. Examples of such semantic relationships are the three different source/target relationships between risk, domain, business process, and enterprise activity, specifying the different kinds of elements responsible for either triggering a risk or being affected by a risk.

\subsection{BPRIM modeling language}

The BPRIM language is designed to enable model-based riskaware business process management. The starting point for the design of this language is the definition of the abstract syntax based on the integrated meta-model of Fig. 5. The second step is to define the concrete syntax, i.e., the graphical symbols used by the modeler to design and by the model user to easily interpret BPRIM models.

Given the intention to facilitate the appropriation of this new language, efforts have been made to reuse process modeling language concepts potential users are likely already familiar with. One of the most relevant languages that fits our needs is the Extended Event-Driven Process Chain (eEPC) [69]. In a previously realized model mapping effort reported in [20], we realized that eEPCs incorporate constructs and a graphical notation for modeling the majority of the concepts introduced by the ISO/DIS 19440 and support the view-based approach. Model views enable clear and precise representation of different aspects of an organization with different levels of abstraction. Another argument for choosing eEPC is its openness for extensions. For example, in an eEPC process diagram, one can graphically specify the objective of an activity and also the physical and human resources required for its imple- 


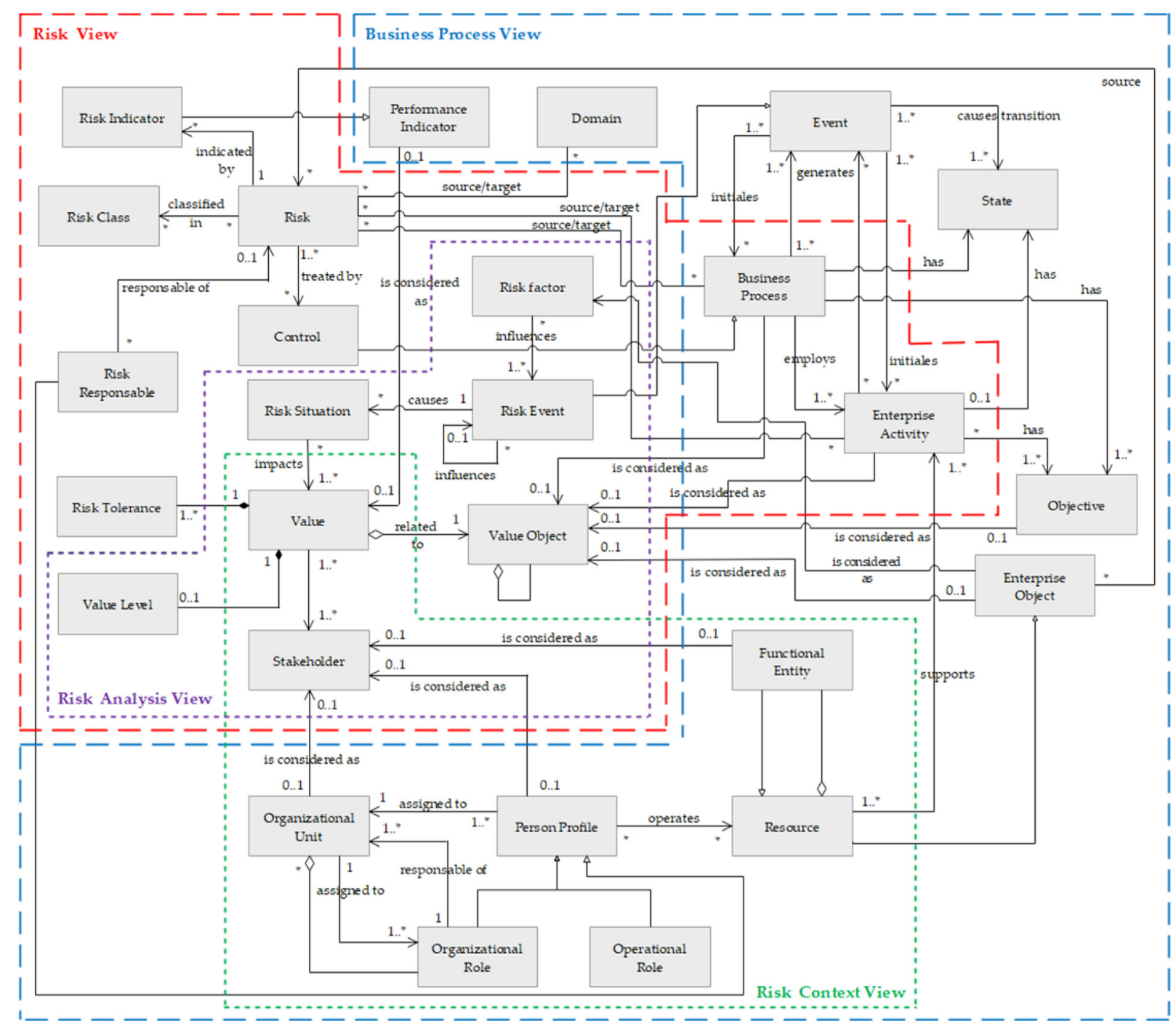

Fig. 5. Excerpt of BPRIM meta-model.

mentation. It is important to note that this ability to represent the organizational elements with a sufficient level of detail (in terms of responsibility, role, and owner) is essential for risk analysis. Hence, it is worth highlighting that the BPMN language is not able to handle this crucial need since it neither permits to connect multiple resource allocations to the same activity, nor to model objectives. We point out that logical operators of EPC correspond to business rules in ISO/DIS 19440.

The BPRIM modeling language reuses eEPC constructs and notations and extends them with additional language constructs for risk-aware business process management by specialization (e.g., event, stakeholder, and process), new operators (e.g., operators between risk and treatment methods), and the related grammar with new relationships (e.g., compositional relationships, generalization between risks) $[19,70,71]$. Table 3 lists the basic elements concerned with risk modeling in BPRIM with their graphical representation.

In order to simplify the inherent complexity of dealing simultaneously with risks and business processes, we have applied a viewing mechanism on top of the integrated BPRIM meta-model. This viewing mechanisms utilizes the complexity reduction mechanism of model viewing by concentrating on selected aspects individually. Consequently, the different views, represented as diagrams, use only a subset of the BPRIM modeling language which reduces the complexity of model creation for users and improves comprehension of models by human beings. The overarching BPRIM model is then re-constructed by combining the information covered in multiple views. Some of the BPRIM diagrams such as EPC and Organigram are well known in enterprise modeling and already integrated into several enterprise modeling tools. Others like the context diagram, risk diagram, and risk analysis diagram have been newly introduced in order to meet the specific needs of BPRIM. Table 4outlines the aims and content of the newly introduced BPRIM diagrams (using bold font).

\section{Implementation of ADOBPRIM on ADOxx}

Technical feasibility of the BPRIM framework is evaluated by a conceptualization and implementation of BPRIM with the ADOxx meta-modeling platform [72]. This section briefly elaborates on the building blocks of ADOxx before the ADOBPRIM tool will be presented.

\subsection{ADOxx meta-modeling platform}

To prepare the ground for the implementation of the BPRIM method as a modeling tool, we have investigated and analysed several meta-modeling platforms such as (EMF) [73], Sirius [74], 
Table 3

Excerpt of the BPRIM modeling language for risk modeling.

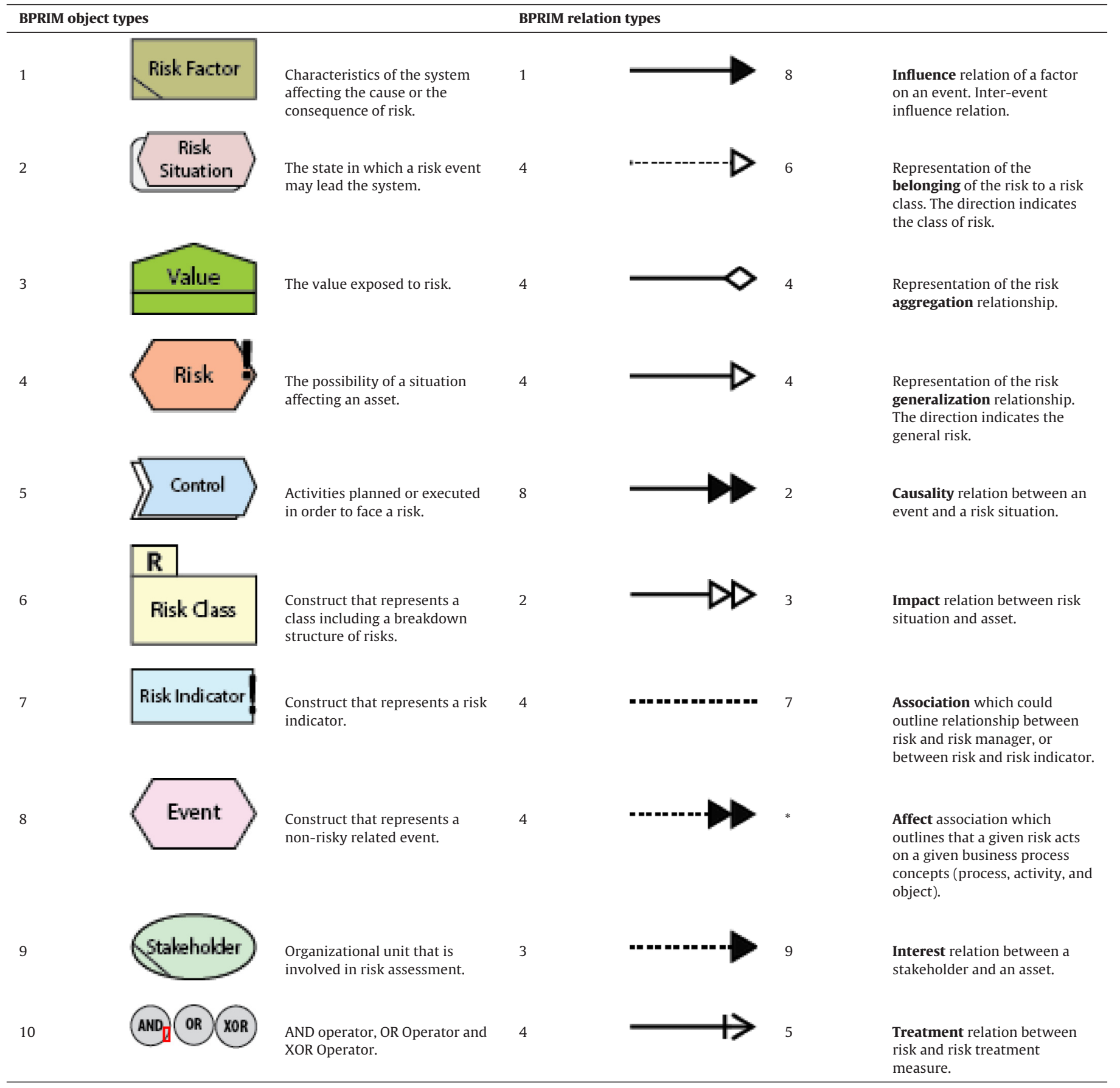

MetaEdit+ [75], Oryx [76], MS DSL Tools [77] and ADOxx [72]. These platforms usually provide many features required for the implementation of modeling tools for graphical modeling languages. The criteria used for the analysis of these platforms are derived from BPRIM requirements and presented in Table 5. The comparison focuses on the software licensing, the user-friendliness, the required knowledge, the collaborative functionality (e.g., multi-user, Repository provision), the ability to accommodate userdefined notations, to support multi-view modeling, to implement user-defined algorithms, to configure objects in models, to query models, to simulate models, and the ability to check models.

Compared to the others, ADOxx is a multi-user platform that provides a repository based on a relational database for meta- models and models. It is built upon the conceptual modeling framework visualized in Fig. 1. To introduce meta-models to ADOxx, no advanced knowledge of a programming language is required - in contrast to the use of the EMF with the Graphical Editing Framework (GEF) and the Graphical Modeling Framework (GMF) which requires a deep knowledge of the Java programming language. In addition, the ADOxx platform provides functionality which facilitates the management of models in the created modeling tool. For instance, ADOxx provides components and modules to analyse, simulate, and evaluate models. Besides, ADOxx has been widely used in industry and academia. In the past twenty years, tool support for more than 40 domain-specific modeling languages has been realized with ADOxx (see [24] for an overview). Based on these 
Table 4

Correspondences between BPRIM models and BPRIM diagrams in the process risk design cycle.

\begin{tabular}{|c|c|c|c|c|}
\hline BPRIM model & Aims & $\begin{array}{l}\text { BPRIM } \\
\text { Life cycle step }\end{array}$ & Content & BPRIM diagram \\
\hline Business Process Model & $\begin{array}{l}\text { Manage relationships and } \\
\text { concepts specific to the } \\
\text { company. }\end{array}$ & Contextualize & $\begin{array}{l}\text { Business Process, } \\
\text { Enterprise Activity, Event, } \\
\text { Data Function, Information, } \\
\text { Resource, Organizational } \\
\text { unit, etc. }\end{array}$ & $\begin{array}{l}\text { - Chain diagram for the } \\
\text { macro process } \\
\text { - Organizational diagram } \\
\text { - EPC diagram }\end{array}$ \\
\hline Risk Context Model & $\begin{array}{l}\text { Manages relationships } \\
\text { among assets, stakeholders } \\
\text { and values. }\end{array}$ & Contextualize & $\begin{array}{l}\text { Organizational unit, } \\
\text { Organizational role, } \\
\text { Operational role, Value, etc. }\end{array}$ & - Risk Context diagram \\
\hline Risk Analysis Model & $\begin{array}{l}\text { Relates causes and } \\
\text { consequences of risk. }\end{array}$ & Assess & $\begin{array}{l}\text { Risk factor, Risk event, Risk } \\
\text { situation, stakeholder, } \\
\text { Value, etc. }\end{array}$ & $\begin{array}{l}\text { - Risk Analysis diagram } \\
\text { - Cause diagram }\end{array}$ \\
\hline $\begin{array}{l}\text { Risk Characterization } \\
\text { Model }\end{array}$ & $\begin{array}{l}\text { Characterize the risk in its } \\
\text { environment }\end{array}$ & Assess & $\begin{array}{l}\text { Risk, Risk class, Risk } \\
\text { indicator, etc. }\end{array}$ & $\begin{array}{l}\text { - Risk extended EPC } \\
\text { diagram } \\
\text { - Risk diagram } \\
\text { - Risk Inventory diagram } \\
\text { - Risk Relationship } \\
\text { diagram }\end{array}$ \\
\hline Risk Mapping Model & $\begin{array}{l}\text { Promote an overview of } \\
\text { risk exposure and support } \\
\text { action decisions. }\end{array}$ & Assess and treat & $\begin{array}{l}\text { Risk, Severity, Likelihood, } \\
\text { Criticality. }\end{array}$ & - Risk Mapping diagram \\
\hline Treatment Scenarios Model & $\begin{array}{l}\text { Manage treatment } \\
\text { scenarios and understand } \\
\text { their effects on risk } \\
\text { mapping. }\end{array}$ & Treat & $\begin{array}{l}\text { Control, Treatment, Risk, } \\
\text { Risk Indicator, etc. }\end{array}$ & $\begin{array}{l}\text { - Risk extended EPC } \\
\text { diagram }\end{array}$ \\
\hline
\end{tabular}

observations, we have chosen the ADOxx platform to implement the BPRIM method and to realize the ADOBPRIM tool.

\subsection{ADOBPRIM modeling tool}

The main goal of the ADoBPRIM modeling tool is to enable the graphical editing of artifacts conforming to the BPRIM meta-model. Moreover, ADOBPRIM will enable to analyse, and asses risks of a business process by following the BPRIM life cycle. In this regard, we have adopted the approach advocated by Bork and Sinz [78] to implement ADOBPRIM with ADOxx. The approach is based on three stages:

1. Introducing the modeling language by defining a mapping between the language concepts and the concepts provided by the ADOxx meta-metamodel [21].

2. Designing the graphical visualization of the modeling language concepts in ADOxx.

3. Implementing mechanisms \& algorithms which process the knowledge captured in the models, thereby increasing the value of the modeling method and the utility of the modeling tool and realizing the modeling procedure.

Fig. 6 gives an overview of the realized ADoBPRIM modeling tool. The ADOBPRIM diagrams (see Table 4) are realized as model types in ADOxx and mapped to specific stages of the BPRIM life cycle (left side of Fig. 6). By this structure, the ADOBPRIM tool guides the user in choosing the right diagram according to the currently engaged BPRIM life cycle stage. As shown on the right side and bottom of Fig. 6, the graphic notation palettes are contextualized according to the model type that the user has selected. In this regard, ADOBPRIM supports multi-view modeling and hides complexity from the user. Based on the BPRIM life cycle, a modeling procedure has been realized which exploits the following mechanisms and algorithms:

- Verification/Validation: verification and validation functionalities are specified on different levels, ranging from cardinality checks as syntactical checks (checking whether all constraints of the BPRIM modeling language are satisfied) to source-target validation. The objective of this mechanism is to ensure the accuracy of diagrams created by checking their structure according to several defined syntactic and semantic rules.

- Risk Assessment: The risk analysis model is analysed and evaluated using a risk assessment matrix. The latter is a classical method to conduct qualitative risk assessment. The objective of this mechanism is to automatically produce a risk matrix which visualizes the different risk levels. To this end, some basic rules should be followed:

$\bigcirc$ The basis for risks to happen is the standard definition of risk criticity as a combination of severity of the consequences and its likelihood. The output risk level is determined by the product of severity of consequences and likelihood, and illustrated in a two dimensional risk matrix.

$\bigcirc$ Severity of consequences, likelihood, and risk level can be divided into different levels, respectively, with qualitative descriptions and scales.

$\bigcirc$ Definitions for the qualitative values (i.e., minor, major, medium, high, very high) were based on qualitative scales defined by the Haute Autorité de Santé (National Authority for Health in France- or HAS).

$\bigcirc$ Based on the acceptance criteria, we defined three risk levels: low, moderate, and high.

The tool has been developed as a project within the Open Models Laboratory, a worldwide community of modelers and modeling method developers [25]. A free download and further information on ADOBPRIM are available through the corresponding project page $^{1}$.

\footnotetext{
1 ADoBPRIM project page [online]: http://austria.omilab.org/psm/content/BPRIM/
} info, last visited: 08.07.2019. 


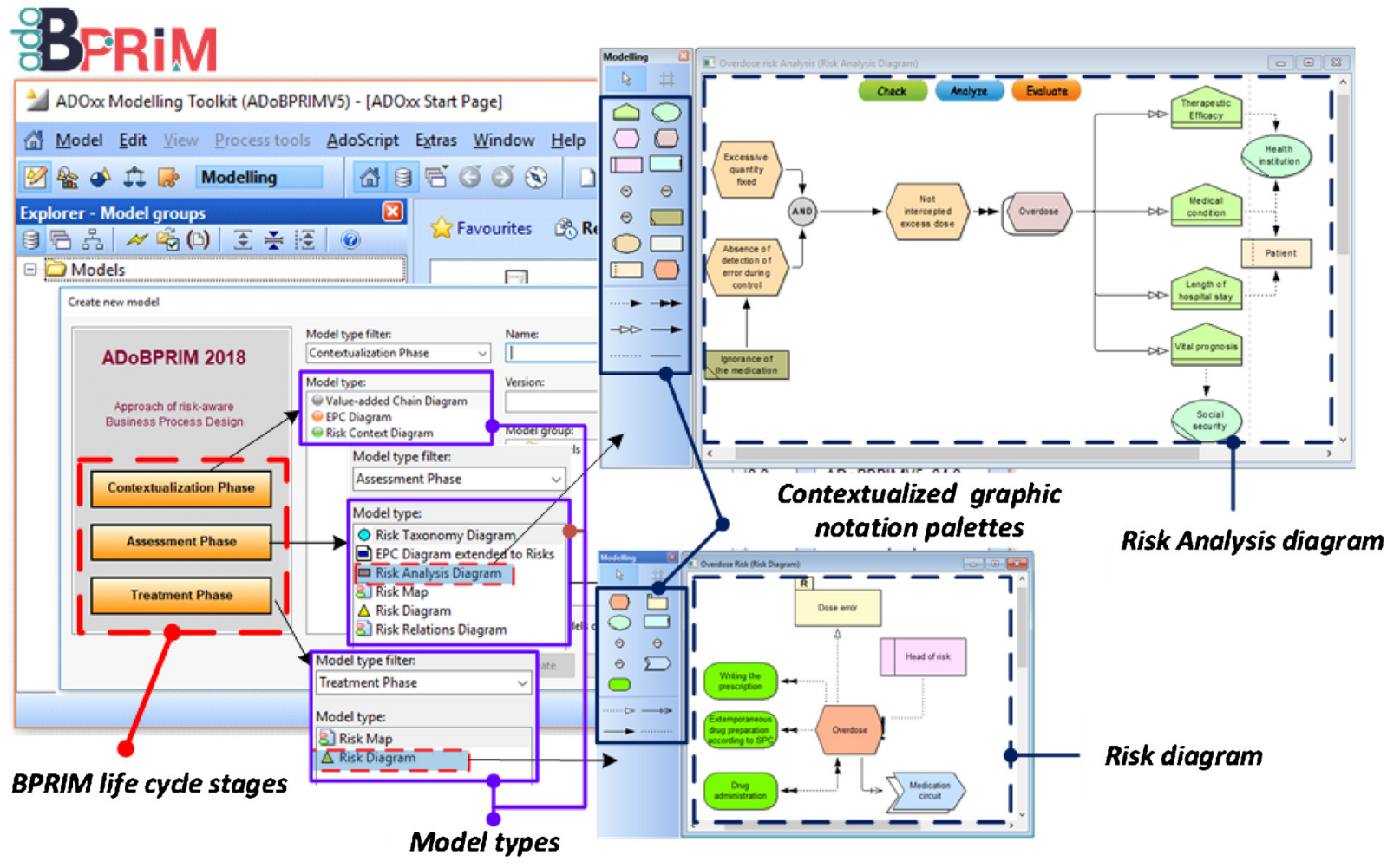

Fig. 6. Overview of the ADoBPRIM modeling tool.

\section{Experimentation and evaluation}

The aim of our experiment is: (1) to evaluate the capabilities of the BPRIM method to analyse risks and business processes in an integrated manner, (2) to determine its advantages and limitations compared to currently used methods, in particular the ALARM (Association of Litigation and Risk Management) method [79], and (3) to identify potential improvements of the proposed approach. For reliable results, similarly to [80], we use a real world case study to evaluate our BPRIM framework. Indeed, we modeled and analysed the medication-use process within an existing hospital in France.

This section is structured as follows: Section 5.1 briefly provides the context of the experimentation. The method used for conducting the experiment is then outlined in Section 5.2. Eventually, Section 5.3 discusses the experimentation results with a focus on lessons learned and requirements for further improvements of BPRIM.

\subsection{Experiment context}

The medication-use process is the fundamental system which provides the basis for safe medication use within the health care environment. Thus, ensuring medications are used and secured in the most appropriate manner and across all settings [81]. It consists in a complex and multidisciplinary process, involving numerous practitioners and it is composed of several stages (i.e., prescribing, dispensing, administration and medication monitoring). Indeed, it may involve up to 36 activities from the moment a doctor considers prescribing medication to the moment when this medication is actually administered or taken by the patient.

This complexity causes a risk of Medication Errors (ME), which can involve serious consequences for the patients. Indeed, in 2015 , the French National Authority for Health (FNAH) considers that $40 \%$ of the serious adverse events are of medication error origin. For this reason, the safety of this process is at the heart of the guardianships in health care facilities. In 1995, the work of Leape and Bates [82] radically changed the way people think about the causes of medication error. They highlighted that error is often the end result of a complex chain of events that either contributes to the error or renders it difficult to detect. Their work demonstrated the need for a systems approach to the medication error problem. Coupled with mounting public concern and awareness of the medication error problem, the physician and pharmacy leaders were sensitized to explore new approaches for medication error management [83].

Currently, some risk management methods are used in health care facilities. These methods essentially focus on teamwork (intervention of pharmacists, doctors, nurses and risk management team) to reduce the number of adverse drug events (ADEs) due to medication errors. Specific structures, called Experience Feedback Committees (EFCs), were created to analyse ADEs within a medical department. An EFC is a multidisciplinary team representing the diversity of the functions encountered in the medical unit. The EFC members meet regularly to examine reported ADEs. The principle is to choose only one ADE per meeting in order to analyse it thoroughly and propose corrective actions. The choice is based either on the severity of the event or on its likelihood.

To analyse an ADE, the committee uses the so-called ALARM (Association of Litigation and Risk Management) method [79]. ALARM aims to get a picture-pause of the current situation and to identify the latent factors that have contributed to cause the ADE so as to set up error reduction strategies. Medication errors may be classified according to the stage of the medication-use process in which they occur (prescribing, dispensing, administration or monitoring).

The experiments have been conducted with the Intercommunal Hospital Center of Castres-Mazamet (CHIC) and focus on the quality control of its medication-use process for elderly in the Geriatric department. This choice is largely motivated by the fact that older adults are at a greater risk of medication errors. Indeed, they tend to take multiple medications (i.e., five or more prescribed drugs) during a day, referred as poly-pharmacy. In such multiple medi- 


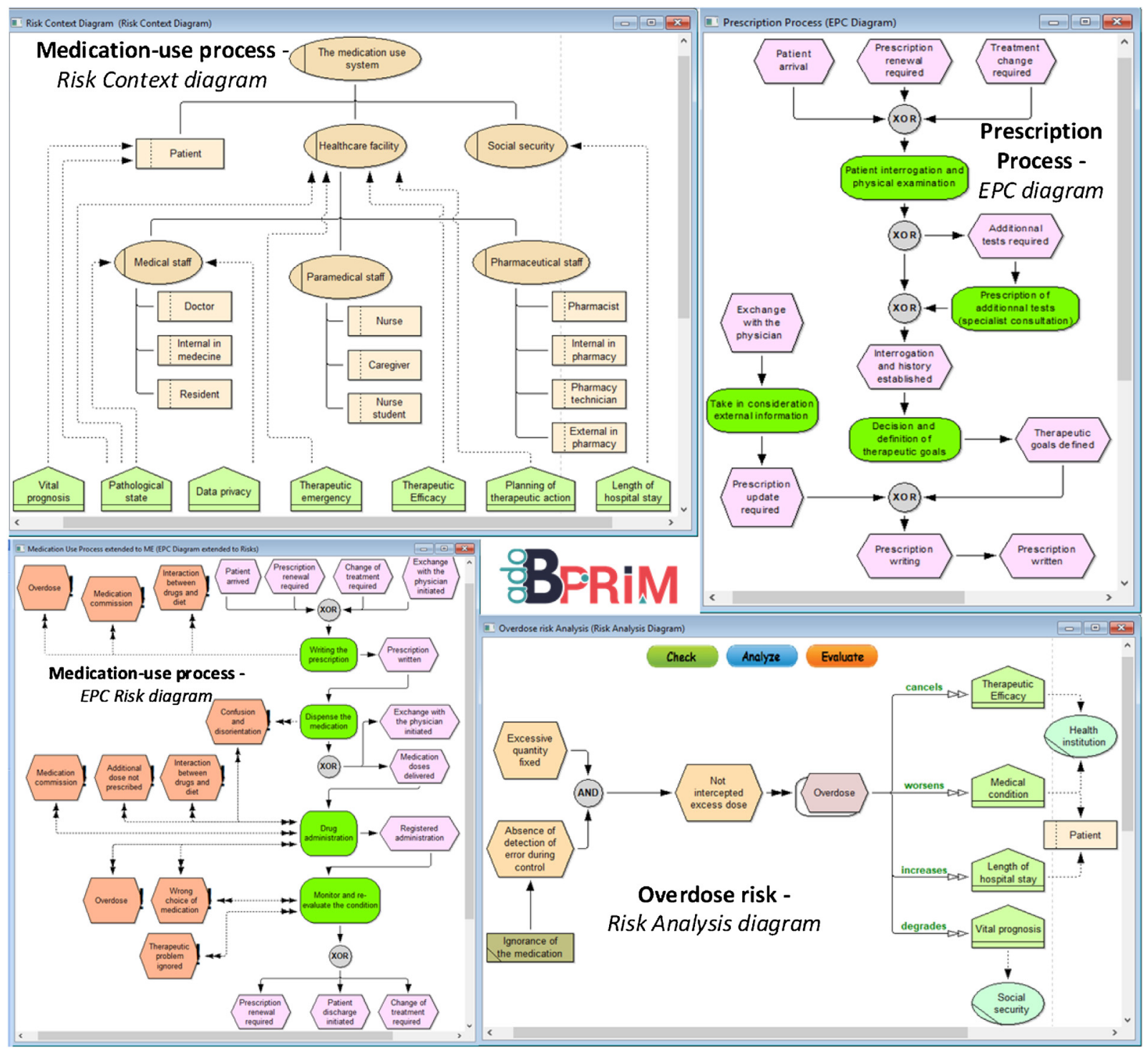

Fig. 7. Risk Context (top left), EPC (top right), Risk extended EPC (bottom left), and Risk Analysis (bottom right) diagrams in ADoBPRIM.

cation settings, quality and safety of the medication use process is highly sensitive.

\subsection{Experiment method}

The experiment was carried out in four main stages over a period of six months. Several actors of the CHIC were involved in this experiment, specifically two doctors, three nurses, two pharmacists, one pharmacy technician, and the Quality Manager of the hospital.

- In the first stage of experimentation, we observed the medication-use process in the Geriatric department at CHIC in order to define the study perimeter, to identify the involved stakeholders, and to create the as-is models of the medicationuse process. At this stage, it is worth noting that a training was provided for the identified stakeholders to introduce the main concepts of BPRIM and to show the use of the ADOBPRIM tool. A focus at this stage was for participants to discover the different BPRIM diagrams and to understand their aims. The deliverable at this stage was one context diagram, four value-added chain diagrams and 14 EPC diagrams presenting a detailed functional and organizational view on the medication-use process in the
Geriatric department. These diagrams were created and validated in collaboration with the experimentation team. All participants agreed on the models, representing the current way to perform the process.

- In the second stage we observed the risk management method which is currently used in this department. To this end, we have joined and participated in an Experience Feedback Committee meeting where an Adverse Drug Event was analysed by a multidisciplinary team using the ALARM method.

- In the third stage of experimentation, we studied 10 real serious ADEs that have been reported by professionals related to the medication-use process in Geriatric department at CHIC. The ADEs had been analysed by the EFC using the ALARM method. The aim of this stage was to analyse these ADEs with the BPRIM method and compare the gained results with those produced by the ALARM method. To this end, we analysed, for each ADE, potential and reported facts and risk events that contribute to the ADE occurrence. Afterwards, we evaluated each ADE using the risk matrix defined by the French National Authority for Health (HAS). The deliverable at this stage was one BPRIM Risk diagram and one BPRIM Risk Analysis diagram for each ADE. After all ADEs were analysed, a BPRIM Risk Map was produced that ranked all ADEs by criticality order (as shown in Fig. 8). These diagrams 


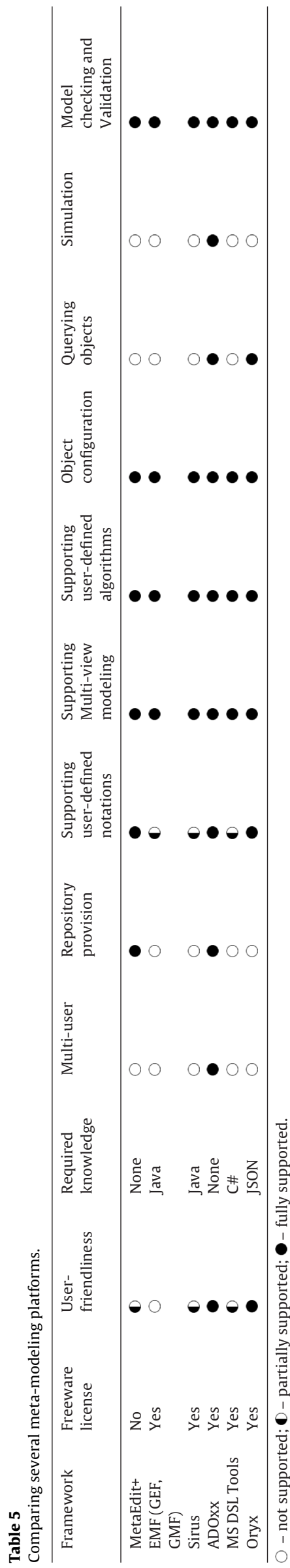

were also subsequently validated by the experimentation team. This enabled us to trace advantages and current weakness of our approach.

- In the last stage of the experimentation we dealt with the validation and evaluation of the overall experiment results. It was performed in accordance with the stakeholders involved with this experimentation and other staff at CHIC. At this stage, value creation and preservation were deeply discussed.

The repository of models developed during the experimentation currently holds around 50 BPRIM models validated in collaboration with end-users (doctors and supporting project partners), some of which are presented in Fig. 7.

\subsection{Experiment results}

This experimentation allows us to evaluate the feasibility and the relevance of the BPRIM framework with respect to its support of Risk-aware Business Process Management. Moreover, we are able to compare BPRIM to an existing method which was used at CHIC. Regarding the chosen application field, it is worth noting that people in charge of the medication-use process and health system at large, are not yet familiar with R-BPM approaches and that their risk management tools are often limited to the use of simple spreadsheet files listing the most frequent risks. This is why the use of the BPRIM framework has been proved more efficient than the traditional method since it was able to formalize more knowledge about risks allowing more comprehensive analysis in a business process context. BPRIM evolves the state of the art from survey based methods with literal means of investigation and analysis to a graphic based method with algorithms.

By carrying out a critical view of the used risk method in CHIC, we can say that error is often the end result of a complex chain of various factors and risk events that contributes to the ADEs occurrence. Therefore, analysis of ADEs should focus on the vulnerabilities of the medication-use process rather than on individual errors. Thus, key to analysing ADEs is a well understood medication-use process that sheds light to the vulnerabilities and weaknesses related to the organization. This is why the BPRIM method recommends to create an as-is view of the system under study prior to the analysis stage.

Thanks to the ADOBPRIM tool, we efficiently designed more than 50 diagrams that allowed us to place the identified risks in their business process context and to automatically evaluate them in order to prioritize the potential risks. As a result, a broader knowledge base has been established, which is useful for the effective management of the hospital medication-use process and compliance control. This knowledge base was shared, thanks to ADOBPRIM, among several actors involved within this process for checking and validation.

This experimentation revealed that new users of ADOBPRIM easily adopted the tool which enabled them to enhance the knowledge base by adding several new diagrams and linking them to other related diagrams. Users also argue on the gain they will achieve by sharing the knowledge base with colleagues. Indeed, it allows them to have a comprehensive vision of risks which is not limited to the medical department which they belong to, as it was the case with the ALARM method. It has been also valued as a useful brainstorming tool for improving the quality of pharmacological management as well as the patient care processes.

Besides, undertaking this experimentation has led to figure out three major weaknesses of the current prototype of the ADOBPRIM tool which will be dealt with in future versions. The first one is related to consistency of multi-view models. As shown in Fig. 5, BPRIM Meta-model comprises views on risk, business process, organization, and value. These multiple views bring inevitable syn- 

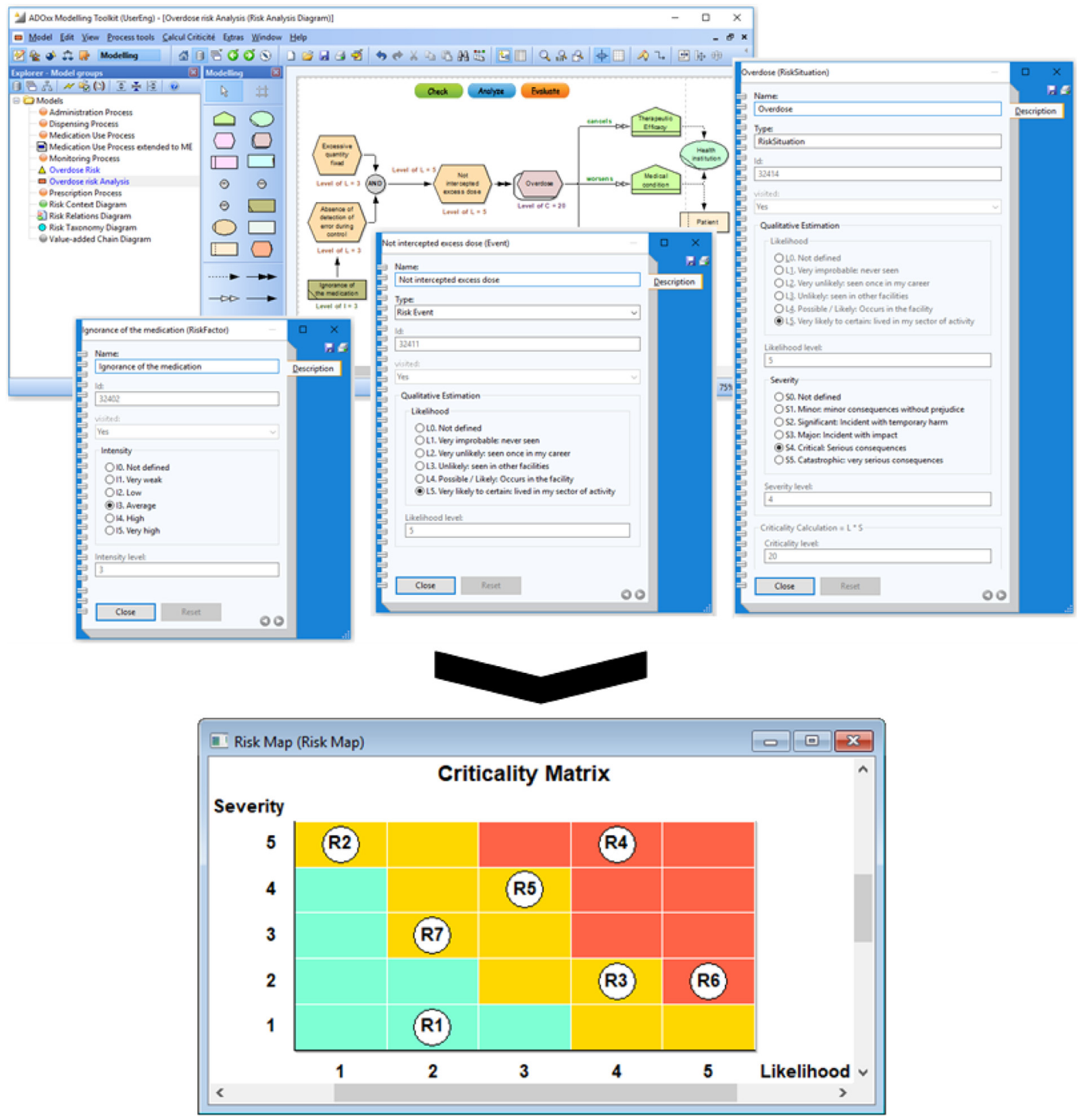

Fig. 8. Evaluation of ADE accordingly to the French National Authority for Health recommendations.

tactically and semantically overlaps when establishing the different diagrams under ADOBPRIM. In this context, it will be crucial for the utility and the applicability of our multi-view modelling method to keep these multiple views consistent and provide suitable visualizations. The second weaknesses concerns the risk evaluation method implemented in ADOBPRIM. Currently, we only use a qualitative method. It will be also interesting to integrate quantitative evaluation methods for a more comprehensive risk analysis. The third weakness points out to the lack of algorithms and mechanisms in order to study the risks propagation and their impact on values created by activities and which are interesting for stakeholders.

\section{Conclusion}

Risk consideration in enterprise engineering is of increasing importance since the business environment is becoming more and more competitive and unpredictable. This need has given rise to the risk-aware business process management (R-BPM) paradigm. It consists of the integration of risk aspects into business process management in order to increase the risk-awareness of an organization's business processes. R-BPM aims to improve global performance and robustness of business process management by enabling a strong collaboration between process and risk management teams.

Investigations and literature analysis that we conducted revealed the weakness of this paradigm with regard to maturity and theoretical foundations, which is necessary for structure, experiments and comprehensiveness, for the scientists as well as for professional practitioners. This research was therefore motivated by these needs.

Our main contribution consists in the design of the BPRIM framework as a path toward the first foundations for risk-aware business process management. Adopting the vision of method concept from information technologies and drawing upon the prin- 
ciples of enterprise architecture, BPRIM suggests an integrative approach with three components:

- A BPRIM life cycle based on coupling the stages of existing BPM and ERM life cycles. Considering information exchanged between the synchronized life cycle of process design and risk management, a set of models was identified and realized as diagrams regarding the input and output of each step.

- A conceptual unification of risk and process based on the coupling between the process meta-model proposed by the ISO/DIS 19440 and the risk meta-model that we have defined at a generic level. In this context, the concept of value has played the role of keystone between these two meta-models.

- A semi-formal graphical modeling language with meta-model and notation. We extended the ISO/DIS 19440 constructs with a new set of constructs for risk modeling. The outcome is a model, which is considered as the abstract syntax of risk enriched process-modeling languages. In order to support an operational usage, a visual concrete syntax is proposed by extending the eEPC notation.

For modeling artefacts conforming to the BPRIM language and automatically assign risks at a business process level following to the BPRIM life cycle, a dedicated modeling tool called ADoBPRIM has been built on the ADOxx platform and was may openly available through the OMiLAB [25].

For evaluation purposes we applied the BPRIM method and the ADOBPRIM tool to the quality control of pharmacological management in a French hospital. We have chosen this application domain because the medication-use process in hospitals is a complex and knowledge-intensive one. Here, any process stage is indeed a source of potential errors that may cause risks to the patient's health. It is also a highly regulated process for which risk management practices have become an imperative by public authorities.

Thanks to the BPRIM method, we have analysed risks in their business process context and we were able to evaluate them accordingly. The results obtained thanks to the ADOBPRIM tool were verified and validated by professionals in the field and were largely concordant or even more relevant in several cases than those obtained by the currently used method. Of course, this method is not limited to the health care sector. The generic character of the BPRIM meta-model makes it usable to any other sector, such as civil engineering, transportation, crisis management, etc.

Besides, the feedback gained from the experiment reveals few shortcomings about the current version of the ADOBPRIM implementation which remain acceptable given its young maturity which is emphasized on the design-time stage. To overcome these weaknesses, we are currently working on a new version of ADOBPRIM, which will integrate new functionalities for risk management. We intend to enhance the run-time stage by adding new features to the modeling environment such as simulation capabilities to: study risk propagation, evaluate risk impact, and stress test control mechanisms. To these ends, currently the laboratory is conducting PhD research on business continuity management and risk propagation analysis methods, the results of which will refine the proposed BPRIM method and extend the ADOBPRIM tool.

\section{Conflict of interest}

None declared.

\section{Acknowledgements}

The authors would like to show their gratitude to the Intercommunal Hospital Center of Castres-Mazamet and more specifically
Dr. CUFI, the head of the Geriatric Department and Dr. CLEOSTRATE, the head of Inpatient Pharmacies who allowed us to evaluate our BPRIM method and ADOBPRIM tool on a real case and provided insights and expertise that greatly enhanced this research. We would also like to thank OMiLAB members for assistance with the ADOxx platform and for providing a collaborative space on their OMiLAB portal.

\section{References}

Benedict, T., Bilodeau, N., Vitkus, P., Powell, E., Morris, D., Scarsig, M., Lee, D., Field, G., Lohr, T., Saxena, R., Fuller, M., Furlan, J., 2013. BPM CBOK Version 3.0: Guide to the Business Process Management Common Body of Knowledge, 3rd ed. CreateSpace/ABPMP - Association of Business Process Management Professionals.

Dumas, M., La Rosa, M., Mendling, J., Reijers, H.A., 2018. Fundamentals of Business Process Management. Springer Berlin Heidelberg, Berlin, Heidelberg.

Burlton, R.T., 2001. Business Process Management: Profiting From Process. SAMS publishing, Indianapolis, USA.

Franz, P., Kirchmer, M., 2014. Value-Driven Business Process Management: The Value-Switch for Lasting Competitive Advantage. McGraw-Hill Professional, New York; Mexico City.

Blyth, M., 2009. Business Continuity Management: Building An Effective Incident Management Plan. John Wiley \& Sons, Hoboken, NJ.

Rejeb, O., Bastide, R., Lamine, E., Marmier, F., Pingaud, H., 2012. A model driven engineering approach for business continuity management in e-health systems. 6th IEEE International Conference on Digital Ecosystems, Technologies (DEST) $1-7$.

Chapman, R.J., 2011. Simple Tools and Techniques for Enterprise Risk Management, 2nd ed. John Wiley \& Sons, Chichester.

Nacer, A.A., Godart, C., Rosinosky, G., Tari, A., Youcef, S., 2019. Business process outsourcing to the cloud: balancing costs with security risks. Comput. Ind. 104, 59-74.

Radanliev, P., De Roure, D.C., Nicolescu, R., Huth, M., Montalvo, R.M., Cannady, S. Burnap, P., 2018. Future developments in cyber risk assessment for the internet of things. Comput. Ind. 102, 14-22.

Bernus, P., Goranson, T., Gøtze, J., Jensen-Waud, A., Kandjani, H., Molina, A., Noran, O., Rabelo, R.J., Romero, D., Saha, P., et al., 2016. Enterprise engineering and management at the crossroads. Comput. Ind. 79, 87-102.

Rosemann, M., Muehlen, M.z., 2005. Integrating Risks in Business Process Models. ACIS 2005 Proceedings.

Dickstein, D.I., Flast, R.H., 2008. No Excuses: A Business Process Approach to Managing Operational Risk, 1st ed. Wiley, Hoboken, NJ.

Jakoubi, S., Neubauer, T., Tjoa, S., 2009. A roadmap to risk-aware business process management. 2009 IEEE Asia-Pacific Services Computing Conference (APSCC 2009), 23-27.

Jakoubi, S., Tjoa, S., Goluch, S., Kitzler, G., 2010. Risk-aware business process management-establishing the link between business and security. Complex Intell. Syst. Appl., 1-26.

Suriadi, S., Weib, B., Winkelmann, A., ter Hofstede, A.H.M., Adams, M., Conforti, R, Fidge, C., Rosa, M.L., Ouyang, C., Rosemann, M., Pika, A., Wynn, M., 2014. Current research in risk-aware business process management - overview, comparison and gap analysis. Commun. AIS 34.

Lankhorst, M., 2012. Enterprise Architecture at Work: Modelling, Communication and Analysis, 3rd ed. Springer, Berlin.

Hinkelmann, K., Gerber, A., Karagiannis, D., Thoenssen, B., Van der Merwe, A. Woitsch, R., 2016. A new paradigm for the continuous alignment of business and it: combining enterprise architecture modelling and enterprise ontology. Comput. Ind. 79, 77-86.

Sienou, A., Karduck, A., Pingaud, H., 2006. Towards a framework for integrating risk and business process management. IFAC Proc. Vol. 39, 647-652.

Sienou, A., Lamine, E., Pingaud, H., Karduck, A., 2009. Aspects of the BPRIM language for risk driven process engineering. In: Meersman, R., Herrero, P., Dillon, T. (Eds.) On the Move to Meaningful Internet Systems: OTM 2009 Workshops, Vol. 5872. Springer-Verlag Berlin, pp. 172-183.

Sienou, A., 2009. Proposition d'un cadre méthodologique pour le management intégré des risques et des processus d'entreprise (Ph.D. thesis). Institut National Polytechnique de Toulouse.

Karagiannis, D., Kühn, H., 2002. Metamodelling platforms. E-Commerce and Web Technologies, Third International Conference, EC-Web 2002, Aix-En-Provence, France, September 2-6, Proceedings, 182.

Mylopoulos, J., 1992. Conceptual Modelling and Telos, Conceptual Modelling, Databases, and CASE: An Integrated View of Information System Development John Wiley \& Sons, New York, pp. 49-68.

Bork, D., Fill, H.-G., 2014. Formal aspects of enterprise modeling methods: a comparison framework. 2014 47th Hawaii International Conference on System Sciences (HICSS), 3400-3409.

Karagiannis, D., Mayr, H.C., Mylopoulos, J. (Eds.), 2016. Domain-Specific Conceptual Modeling, Concepts, Methods and Tools. Springer.

Bork, D., Buchmann, R.A., Karagiannis, D., Lee, M., Miron, E.-T., 2019. An open platform for modeling method conceptualization: the OMiLAB digital ecosystem. Commun. Assoc. Inform. Syst. 44, 673-697.

Dallas, M.F., 2011. Value and Risk Management: A Guide to Best Practice. WB, Oxford, Malden, MA. 
ter Hofstede, A., 2011. Risk-Aware Business Process Management., pp. 00035.

Jans, M., Van Der Werf, J.M., Lybaert, N., Vanhoof, K., 2011. A business process mining application for internal transaction fraud mitigation. Expert Syst. Appl. 38, 13351-13359.

Wickboldt, J.A., Bianchin, L.A., Lunardi, R.C., Granville, L.Z., Gaspary, L.P., Bartolini, C., 2011. A framework for risk assessment based on analysis of historical information of workflow execution in it systems. Comput. Netw. 55, 2954-2975.

Panayiotou, N.A., Oikonomitsios, S., Athanasiadou, C., Gayialis, S.P., 2011. Risk assessment in virtual enterprise networks: a process-driven internal audit approach. Global Business: Concepts, Methodologies, Tools and Applications, IGI Global, 888-910.

Rogge-Solti, A., Weske, M., 2015. Prediction of business process durations using nonMarkovian stochastic petri nets. Inform. Syst. 54, 1-14.

Weiss, B., Winkelmann, A., 2011. Developing a process-oriented notation for modeling operational risks - a conceptual metamodel approach to operational risk management in knowledge intensive business processes within the financial industry. 44th Hawaii International Conference on System Sciences (HICSS), $1-10$.

Haggag, M.H., Khedr, A.E., Montasser, H.S., 2015. A risk-aware business process management reference model and its application in an Egyptian university. Int. J. Comput. Sci. Eng. Surv. 6, 11.

Rotaru, K., Wilkin, C., Churilov, L., Neiger, D., Ceglowski, A., 2011. Formalizing process-based risk with value-focused process engineering. Inform. Syst. EBusiness Manag. 9, 447-474.

Pika, A., van der Aalst, W.M., Wynn, M.T., Fidge, C.J., ter Hofstede, A.H., 2016. Evaluating and predicting overall process risk using event logs. Inform. Sci. 352, 98-120.

Strecker, S., Heise, D., Frank, U., 2011. Riskm: a multi-perspective modeling method for it risk assessment. Inform. Syst. Front. 13, 595-611.

Conforti, R., Fink, S., Manderscheid, J., Röglinger, M., 2016. Prism - a predictive risk monitoring approach for business processes. International Conference on Business Process Management, 383-400.

Fenz, S., 2010. From the resource to the business process risk level. In: Proceedings of the South African Information Security Multi-Conference: Port Elizabeth, South Africa, May 17-18, Lulu.com, p. 100.

Kim, J., Lee, J., Lee, J., Choi, I., 2017. An integrated process-related risk management approach to proactive threat and opportunity handling: a framework and rule language. Knowl. Process Manag. 24, 23-37.

Bai, X., Krishnan, R., Padman, R., Wang, H.J., 2012. On risk management with information flows in business processes. Inform. Syst. Res. 24, 731-749.

Metzger, A., Bohn, P., 2017. Risk-based proactive process adaptation. International Conference on Service-Oriented Computing, 351-366.

Shabnam, L., Haque, F., Bhuiyan, M., Krishna, A., 2014. Risk measure propagation through organisational network. IEEE 38th International Computer Software and Applications Conference Workshops, 217-222.

Lhannaoui, H., Kabbaj, M.I., Bakkoury, Z., 2014. Analyzing risks in business process models using a deviational technique. 9th International Conference on Software Engineering and Applications (ICSOFT-EA), 189-194.

Shah, L.A., Etienne, A., Siadat, A., Vernadat, F., 2017. Process-oriented risk assessment methodology for manufacturing process evaluation. Int. J. Prod. Res. 55, 4516-4529.

Pittl, B., Fill, H.-G., Honegger, G., 2017. Enabling risk-aware enterprise modeling using semantic annotations and visual rules. Proceedings of the 25th European Conference on Information Systems (ECIS).

Cope, E., Küster, J.M., Etzweiler, D., Deleris, L., Ray, B., 2009. Risk Extensions to the BPMN 1.1 Business Process Metamodel, Technical Report RZ3740. IBM Research, 00003.

Cope, E.W., Kuster, J., Etzweiler, D., Deleris, L.A., Ray, B., 2010. Incorporating risk into business process models. IBM J. Res. Dev. 54, 1-4.

E.W. Cope, L.A. Deleris, D. Etzweiler, J. Koehler, J.M. Kuester, B.K. Ray, System and method for creating and expressing risk-extended business process models, US Patent 8,862,491 (2014).

Varela-Vaca, A.J., Gasca, R.M., Pozo, S., 2011. Opbus: risk-aware framework for the conformance of security-quality requirements in business processes. In: Proceedings of the International Conference on Security and Cryptography. IEEE, pp. 370-374.

Varela-Vaca, A.J., 2016. Opbus: a framework for improving the dependability of riskaware business processes. AI Commun. 29, 233-235.

Haley, C.B., Moffett, J.D., Laney, R., Nuseibeh, B., 2006. A framework for security requirements engineering. In: Proceedings of the 2006 International Workshop on Software Engineering for Secure Systems. ACM, pp. 35-42.

Marcinkowski, B., Kuciapski, M., 2012. A business process modeling notation extension for risk handling. In: IFIP International Conference on Computer Information Systems and Industrial Management. Springer, pp. 374-381.

Altuhhov, O., Matulevičius, R., Ahmed, N., 2013. An extension of business process model and notation for security risk management. Int. J. Inform. Syst. Model. Des. 4, 93-113.

Jakoubi, S., Tjoa, S., Quirchmayr, G., 2007. Rope: a methodology for enabling the risk-aware modelling and simulation of business processes. ECIS, 1596-1607.
Jakoubi, S., Tjoa, S., Goluch, S., Kitzler, G., 2010. Risk-aware business process management-establishing the link between business and security. In: Complex Intelligent Systems and Their Applications. Springer, pp. 109-135.

Tjoa, S., Jakoubi, S., Goluch, G., Kitzler, G., Goluch, S., Quirchmayr, G., 2011. A formal approach enabling risk-aware business process modeling and simulation. IEEE Trans. Serv. Comput., 153-166.

Jakoubi, S., Tjoa, S., Goluch, S., Kitzler, G., 2010. A formal approach towards risk-aware service level analysis and planning. In: International Conference on Availability, Reliability and Security. IEEE, pp. 180-187.

Betz, S., Hickl, S., Oberweis, A., 2011. Risk-aware business process modeling and simulation using xml nets. In: IEEE 13th Conference on Commerce and Enterprise Computing (CEC). IEEE, pp. 349-356.

Frank, U., 2011. The MEMOMeta Modelling language (MML) and Language Architecture, Technical Report. ICB-Research Report.

Bork, D., Karagiannis, D., Pittl, B., 2020. A survey of modeling language specification techniques. Inform. Syst. 87, http://dx.doi.org/10.1016/j.is.2019.101425.

Conforti, R., de Leoni, M., La Rosa, M., van der Aalst, W.M., 2013. Supporting risk-informed decisions during business process execution. In: Advanced Information Systems Engineering. Springer, pp. 116-132.

ISO, 2009. 31000:2009 Risk Management - Principles and Guidelines.

von Scheel, H., von Rosing, M., Hove, M., Fonseca, M., Foldager, U., 2015. Phase 2: process concept evolution. In: von Rosing, M., Scheer, A.-W., von Scheel, H. (Eds.), The Complete Business Process Handbook. Morgan Kaufmann, pp. 11-35.

ISO, 2007. 19440: 2007 Enterprise Integration - Constructs for Enterprise Modelling.

Sienou, A., Karduck, A.P., Lamine, E., Pingaud, H., 2008. Business process and risk models enrichment: Considerations for business intelligence. In: IEEE International Conference on E-Business Engineering. IEEE, pp. 732-735.

Philippe, L., 2003. Méthodes et pratiques de la performance. Le pilotage par les processus et les compétences. Editions d'Organisation, Paris.

Bosch, M., 2007. Modelisation pour la simulation de chaines de production de valeur en entreprise industrielle comme outil d'aide a la decision en phase de conception/industrialization (Ph.D. thesis, Thèse de doctorat). IRCCyN, Ecole centrale de Nantes, Université de Nantes, Nantes, FR.

Hammer, M., Champy, 1993. Reengineering the Corporation: A Manifesto for Business Revolution. Nicholas Brealy, London (1).

Davis, R., Brabander, E., 2007. ARIS Design Platform: Getting Started with BPM. Springer Science \& Business Media.

Sienou, A., Lamine, E., Karduck, A.P., Pingaud, H., 2008. Towards a semi-formal modeling language supporting collaboration between risk and process manager. In: 2nd IEEE International Conference on Digital Ecosystems and Technologies. IEEE, pp. 119-125.

Sienou, A., Lamine, E., Karduck, A., Pingaud, H., 2007. Conceptual model of risk: towards a risk modelling language. Web Information Systems Engineering WISE 2007 Workshops, WISE 2007 International Workshops, Nancy, France, December 3. Proceedings, 118-129.

ADOxx.org, 2019. The Adoxx Metamodeling Platform (Last accessed 27 June 2019) www.adoxx.org.

McNeill, K., 2008. Metamodeling with EMF: generating concrete, reusable java snippets. Extend Eclipse Ecore Metamodel IBM 21.

Viyovic, V., Maksimovic, M., Perisic, B., 2014. Sirius: a rapid development of DSM graphical editor. IEEE 18th International Conference on Intelligent Engineering Systems INES, 233-238.

Tolvanen, J.-P., Rossi, M., 2003. Metaedit+: defining and using domain-specific modeling languages and code generators. In: Companion of the 18th Annual ACM SIGPLAN Conference on Object-Oriented Programming, Systems, Languages, and Applications. ACM, pp. 92-93.

Decker, G., Overdick, H., Weske, M., 2008. Oryx - an open modeling platform for the BPM community. In: Dumas, M., Reichert, M., Shan, M.-C.(Eds.), Business Process Management, Lecture Notes in Computer Science. Springer Berlin Heidelberg, pp. 382-385.

Cook, S., Jones, G., Kent, S., Wills, A., 2007. Domain-Specific Development with Visual Studio DSL Tools, 1 st Ed. Addison-Wesley Professional.

Bork, D., Sinz, E.J., 2010. Design of a SOM business process modelling tool based on the ADOxx meta-modelling platform. In: Pre-Proceedings of the 4th International Workshop on Graph-Based Tools. University of Twente, Enschede, pp. 90-101.

Vincent, C., Taylor-Adams, S., Chapman, E.J., Hewett, D., Prior, S., Strange, P., Tizzard, A., 2000. How to investigate and analyse clinical incidents: clinical risk unit and association of litigation and risk management protocol. BMJ 320, 777-781.

Barcelona, M., Garc\&rsquo;í-Borgo nón, L., Escalona, M., Ramos, I., 2018. Cbgframework: a bottom-up model-based approach for collaborative business process management. Comput. Ind. 102, 1-13.

Vest, T.A., Gazda, N.P., Schenkat, D.H., Eckel, S.F., 2019. Practice-enhancing publications about the medication use process in 2017. Am. J. Health-Syst. Pharm.

Leape, L.L., Bates, D.W., Cullen, D.J., Cooper, J., Demonaco, H.J., Gallivan, T., Hallisey, R., Ives, J., Laird, N., Laffel, G., et al., 1995. Systems analysis of adverse drug events. JAMA 274, 35-43.

Bevilacqua, M., Ciarapica, F., Mazzuto, G., 2018. Fuzzy cognitive maps for adverse drug event risk management. Saf. Sci. 102, 194-210. 